
Not for reproduction, distribution or commercial use.

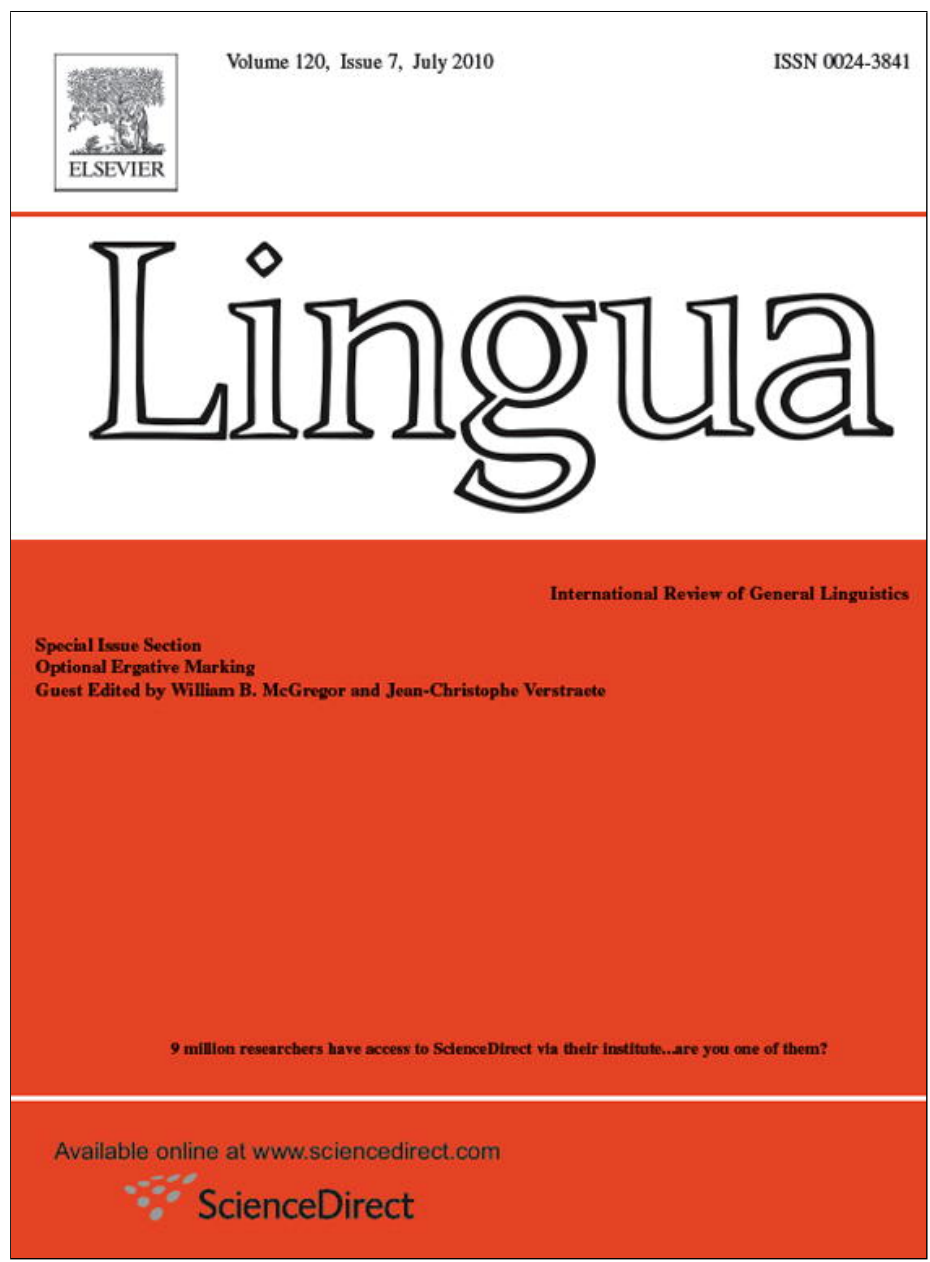

This article appeared in a journal published by Elsevier. The attached copy is furnished to the author for internal non-commercial research and education use, including for instruction at the authors institution and sharing with colleagues.

Other uses, including reproduction and distribution, or selling or licensing copies, or posting to personal, institutional or third party websites are prohibited.

In most cases authors are permitted to post their version of the article (e.g. in Word or Tex form) to their personal website or institutional repository. Authors requiring further information regarding Elsevier's archiving and manuscript policies are encouraged to visit:

http://www.elsevier.com/copyright 


\title{
'Optional' ergativity and the framing of reported speech
}

\author{
Alan Rumsey* \\ Australian National University, Department of Anthropology, Research School of Asian and Pacific Studies, Canberra, ACT 0200, Australia \\ Received 15 August 2006; received in revised form 18 December 2008; accepted 13 May 2009 \\ Available online 7 August 2009
}

\begin{abstract}
This paper focuses on optional ergative marking in the Papuan language Ku Waru and the Australian Aboriginal language Bunuba, especially in constructions with verbs of speaking. It addresses two interrelated issues: (i) What semantic and pragmatic factors are associated with the difference between ergative and non-ergative subject marking in languages where this is not strictly determined by whether the verb is grammatically transitive or intransitive; (ii) How are we to understand the grammatical relationship between verbs of speaking and the material they frame? In both languages that material behaves in some respects like a grammatical object. These locutionary objects differ among themselves in the extent to which they stand out as distinct speech events in relation to the framing one, and those differences are correlated with the presence or absence of ergative marking on the subject of the framing verb. I argue that Bunuba and Ku Waru optional ergative marking in this context can be accounted for by an extended version of Hopper and Thompson's notion of object individuation, in which the grammar treats the metalinguistic relationship between reported speech and that which reports it as analogous to that between Patient and Agent in canonical transitive clauses.
\end{abstract}

(C) 2009 Elsevier B.V. All rights reserved.

Keywords: Ergativity; Reported speech; Transitivity; Bunuba; Ku Waru

\section{Introduction}

This article concerns one of the uses of optional ergative marking (henceforth OEM) in two languages: Ku Waru, a Papuan language of the Chimbu-Waghi Family (Trans-New Guinea Phylum), spoken in the Western Highlands of Papua New Guinea; and Bunuba, a (non-Pama-Nyungan) Australian Aboriginal language spoken in the Kimberley region of Western Australia. The ergative marking that I will be examining in both languages occurs on the subject NPs, including both lexical NPs and pronouns, of verbs which frame reported speech or thought (see McGregor, 1994 and Rumsey, 1982:157-167 on the concept of 'framing'). By means of a comparison of how this works in the two languages, I will be addressing two interrelated theoretical issues: (i) What semantic and pragmatic factors are associated with the difference between ergative and non-ergative subject marking in languages where this is not strictly determined by whether the verb is grammatically transitive or intransitive; (ii) How are we to understand the grammatical relationship between verbs of speaking and the material which they 'report' or frame?

As an introduction to the kinds of constructions I will be dealing with, consider the following four sentences, two from Bunuba and two from Ku Waru.

\footnotetext{
* Tel.: +61 26125 2365; fax: +61 261253023 .

E-mail address: alan.rumsey@anu.edu.
} 
Bunuba:

(1)
mayi wuruga'ra-ngarragi
milwirri-ingga mi-y
food steal'3SG<3SG:PST:RA2-1sgOBL dove-ERG 3SG:say-PAST
"You have been stealing my food" said the dove.
malngarri nyirramiya mi-y-ngiyirrangu
banga'wunggurra-g
European then 3SG:say-PST-1R.OBL go.back'FUT:2NSG:RA-PL
Then the European used to tell us to go back. [lit.: "you (pl) go back"]

Ku Waru:

(3) $(=56)$ ab-ayl-n kangabola nu-nga nyi-ki-m

woman-DEF-ERG child you-GEN say/speak-PPR-3SG

The woman says: "The child is yours".

(4) (=67) ab-ayl nunu-nga rong-te mol nyi-ki-m-ayl

woman-DEF she herself-GEN fault-IDF no say/speak-PPR-3SG-DEF

The woman says it was not her own fault.

Notice that in (1) and (3), the subject of the verb of speaking is marked with what I have (for reasons presented below) labeled an ergative case, while in (2) and (4) it is not. These sentences are both typical of Bunuba and Ku Waru in that the subjects of framing verbs in both languages are sometimes ergative marked and sometimes not. Below I compare the two languages with respect to the question of what other factors go along with this difference, and what we can learn from it about case-marking systems in general, and in particular about optional ergative marking.

Bunuba and $\mathrm{Ku}$ Waru are genetically unrelated and in most respects very different from each other, but typologically similar in certain ways that make them ideal languages for the purpose of this comparison. Both languages have core case-marking systems of the OEM type (see McGregor, this issue). In both languages, as in most or all other so-called ergative languages, ergative case marking does not occur on all NPs functioning as the subject of a transitive verb. But these languages differ from the by-now well-known 'split ergative' languages such as Dyirbal or Georgian, in that the presence or absence of ergative marking is not predictable according to a hierarchy of lexical features of NP types - nor indeed is it fully predicable according to any context-independent grammatical specifications. In both Bunuba and $\mathrm{Ku}$ Waru the ergative marker can occur on nominal expressions of all types (including personal pronouns) when they are the subject of a bivalent verb or transitive clause, but is not obligatory on any of them. Rather than being fully grammaticalised at the clause level, ergative marking in these languages varies according to a range of semantic and discourse factors.

This being the case, some linguists would not use the term 'ergative' at all for such a system. Dixon (1994:35) for example prefers to use that term only for fully grammaticalised, obligatory marking of the 'A' of transitive verb which never occurs on the ' $S$ ' of an intransitive one. But on any account there is at least a strong family resemblance between the way ergative marking works in these languages and in other languages such as Dyirbal or Jaru which display fully grammaticalised ergativity of the more canonical sort. In Bunuba, for example, informants nearly always include ergative marking on the subjects of bivalent verbs in elicited sentences, and in running texts they use it on nearly $90 \%$ of them (section 3). Other kinds of verbs sometimes have ergative-marked subjects too, but when they do, there is always a reason for it which can be understood in terms of an extended notion of 'transitivity' (section 3 ). The facts are similar in $\mathrm{Ku}$ Waru, albeit with a lower proportion of transitive subjects appearing in ergative case (ca. $62 \%$ in my sample). McGregor (this issue: section 6) provides further arguments for an analysis of OEM systems as ergative ones. Precisely because the core case marking in OEM systems is in some ways more directly related to semantic and pragmatic factors than it is in fully grammaticalised ergative-absolutive systems, study of the former can help us understand the basis of the latter (cf. Merlan and Rumsey, 2001).

\section{Reported speech}

Every human language has formal means for attributing a locution to some other speech situation besides the one in which it is being uttered, cited or referred to - the phenomenon nowadays commonly called 'reported speech' (after Voloshinov, 1973) or 'reported discourse' (Rosier, 1999; Güldemann and von Roncador, 2002). This includes 
quotation, indirect discourse, and a range of even less direct forms of 'framing' to be exemplified below. What they all have in common is that any use of them presupposes two distinct speech situations: a 'reporting' one with respect to which the utterance is immediately anchored and a 'reported' one which is being represented within it. In direct discourse, the values of person, tense, mood and all the other indexical categories of the 'reported' utterance are grounded in the 'reported' speech situation, whereas in (relatively more) 'indirect' varieties, some or all of those values are grounded in the 'reporting' speech situation. Probably every language has at least one verb that can be used to introduce or set off such reported speech from the immediate context of the speech situation - 'say', etc. - which I refer to by the more general term 'framing' verbs, since what is being represented by them is not always something that was explicitly 'said'.

What is the nature of the relationship between such verbs and the material they frame? That issue has been a hotly contested one among philosophers and linguists. Among 'formal' and 'functional' linguists alike (e.g., Rosenbaum, 1967; Stockwell, 1977; Givón, 1980; Noonan, 1985; Ransom, 1986; Dik, 1989; Hengeveld, 1989; Bolkestein, 1990, 1992) the dominant approach has long been to treat the framed material as a syntactic complement - a potentially complex constituent which bears the same relation to the framing verb as does the direct object to a transitive verb. Other analysts including Partee (1973) and Davidson (1968/1969, 1984:79-92) have argued that quotation - in my terms the prototypical kind of framed material - is not a constituent of the sentence which frames it, i.e., bears no structural relationship to the verb which frames it. In some analyses, including that of Partee, this position is combined with one that treats indirect discourse as an embedded complement. Other analysts, including Longacre (1985) and Halliday (1985), reject the idea that either direct or indirect discourse is syntactically embedded. Halliday treats the relation instead as one of dependence (in English at least), a hypotactic one in the case of indirect discourse, and a paratactic one in the case of direct. McGregor (1994) disputes Halliday's position, arguing instead that (for Gooniyandi in any case), the 'framing' relationship is different from any of these, and is a relationship of whole to whole rather than of whole to part or part to whole.

Be that as it may, the fact remains that there is a considerable diversity among the world's languages in how the framing relationship is formally expounded, and in many of them the framed locution is at least in certain respects treated like a grammatical object. This was at least implicitly acknowledged in the pioneering comparative study by Munro (1982), who, however, gave greater emphasis to the evidence in her relatively small sample of languages (about 10 of them) that constructions of "say' plus a quotation" are "syntactically intransitive" (316).

Munro's study was greatly expanded upon by De Roeck (1994), who carried out what is still, as far as I know, the most extensive and systematic comparative study of how the framing relationship is formally expounded in languages of the world. Working with a selected sample of forty languages "in which all phyla and most of the important sub-phyla are represented" (335), De Roeck found that whereas 15 or 37.5\% of them have intransitive or "semitransitive" verbs of saying, 19 or $47.5 \%$ have "only transitive verbs of saying" (337). While the 'only' in this formulation might have to be qualified if fuller data had been available for some of those languages, one can safely conclude that grammatically transitive verbs of saying are at least available in most or all of those 19 languages, and in most of them are probably the most commonly used kind of framing device. The same has been shown to be true in other, more intensive studies of individual languages, including Tamil (Steever, 2002) and Egyptian (Kamerzell and Peust, 2002).

Although De Roeck's study is empirically better grounded than Munro's, and its results in that respect more reliable, it fails to capitalize on what is in my view the most methodologically valuable aspect of Munro's study, namely, the way in which Munro opened up the framing relationship to investigation in terms of the analysis of transitivity that was originally propounded by Hopper and Thompson (1980) and has since been corroborated and refined in many other studies (e.g., Tsunoda, 1985; Vázquez Rozas, 1999; Thompson and Hopper, 2001; Croft, 2002:175-183; Næss, 2007). In this analysis transitivity is not a matter of a simple two-way distinction between transitive and intransitive verbal categories, but a scalar phenomenon, characterised by co-variation ${ }^{1}$ of a number of analytically distinct values including: punctuality and telicity of the verb, conscious activity of the agent, and the degree of individuation and affectedness of the object. It is not a property of the verb per se, but of the entire clause.

This scalar view of transitivity allows us to pose the question about 'say' clauses in a somewhat different way from the views discussed above. Rather than asking whether quotations are direct objects or some other kind of constituent,

\footnotetext{
${ }^{1}$ This covariation is of course not perfect or exceptionless. Indeed there are circumstances under which some of the factors discussed by Hopper and Thompson are regularly opposed to each other. For illuminating discussion see Tsunoda (1985). Compare also Tsunoda (1981), a work which was written before Hopper and Thompson's study was published, and which independently arrived at many of the same conclusions, as well as some other important original insights concerning the phenomena in question.
} 
we can ask: to what extent do clauses of saying display the properties which are cross-linguistically associated with high versus low transitivity? I have addressed this question in some detail with respect to Bunuba elsewhere (Rumsey, 1994), and Francesca Merlan and I have addressed it with respect to Ku Waru (Merlan and Rumsey, 2001). This study builds upon both of those earlier ones by drawing upon larger textual samples - especially with regard to the use of ergative marking in other clauses besides those with verbs of saying - and by comparing the patterns found in each language and trying to draw some more general conclusions from them concerning optional ergativity and the framing of reported speech. I now turn to some background details concerning the relevant syntactic constructions in Bunuba.

\section{Bunuba verbs, clause types and $\mathrm{OEM}^{2}$}

Almost all verbs in Bunuba are what is known in the Australianist literature (e.g., Dixon, 2002; McGregor, 2002; Rumsey, 1982) as 'complex' or 'compound' ones, consisting of an initial, lexically specific 'preverb' (e.g., jira 'fall' in (5) below; gayga 'chop' in (8) below), followed by inflected verb root which bears the pronominal prefixes and other grammatical affixes which pertain to the verb complex a whole. As in many other non-Pama-Nyungan languages of northern Australia, these affixes include a set of obligatory cross-referencing pronominal prefixes for subjects of monovalent verbs, and a separate set of obligatory prefixes for both the subject and object of bivalent verbs. ${ }^{3}$ There are only 10 verb roots, five of them monovalent and five bivalent. Eight of these 10 roots (including all of the bivalent ones) only ever occur with an accompanying preverb, which carries most of the lexical meaning of the resulting verbal expression. The meanings of the roots themselves are generally quite abstract, classificatory ones. Since these are difficult to gloss succinctly, in my interlinear glosses for them here as elsewhere I follow McGregor's (1990) practice for the neighbouring language Gooniyandi and give a citation form of the root in upper case at the appropriate position on the gloss line (WU, WU2, YHA, etc. - except for MA which in some environments can be glossed succinctly as 'say' or 'do').

While similar to most other non-Pama-Nyungan languages in packing much of the grammatical information for the clause into the verb, Bunuba differs from most of the others in that, in Bunuba, an NP which is the subject of a bivalent verb seldom occurs in the same unmarked form that it always takes when occurring as the object of a bivalent verb. Rather, when functioning as the subject of a bivalent verb, the NP usually includes a marker -ingga, which usually occurs on the first word of the NP only, but sometimes on other words within it as well. ${ }^{4}$ For reasons I have indicated in section 1 and will expand upon below, I interpret -ingga when occurring in subject NPs as an ergative marker. The use of monovalent verbs is illustrated in examples (5)-(7), and bivalent verbs with ergative-marked subjects in (8)-(10).

(ngayini) jira'luwani-y

(I) fall'1SG:WA-PST

I fell down.
ngindaji gurama wad'ja-y
mayi-yawu
this man go/come'3SG:RA-PST food-ALL

This man went for food.

\footnotetext{
${ }^{2}$ The data base for this section and the following includes the data used for Rumsey (1994), combined with more recently recorded text material that has been transcribed and translated in Thangani Bunuba (Kimberley Language Resource Centre, 1998) and a Bunuba text recorded and transcribed by Coate (1965). Including that material, the total corpus now includes 79 texts by 20 Bunuba speakers, totaling about 2500 clauses. The spelling system used here is adapted from a Bunuba-approved community orthography, in which retroflex consonants are distinguished from apicoalveolars by underlining and lamino-dental consonants are shown with the digraphs th, nh and yh (for details see Rumsey, 2000:40).

${ }^{3}$ For description and justification of the category of 'subject' in Bunuba see Rumsey (2000:section 3.4.4b and section 4.1.1). For further information on Bunuba verbs see Rumsey (2000:75-105). It should be borne in mind that, in naturally occurring, connected speech in Bunuba, in by far the majority of clauses the pronominal affixes on the verb provide the only overt reference to the major participants in the clause (the subject and object of the verb), as these are generally established via discourse cohesion with previous clauses. Integrally related to this reference-tracking function, the pronominal affixes also provide the only overt indication of the major syntactic functions for those implicit referents, since the nominal case-marking option is available only where there are NPs to be marked. In a sample of 100 clauses with bivalent verbs (taken from Wirrunmarra et al., 1990:1-20) only 17 (17\%) had a subject in the same clause.

${ }^{4}$ As in many, perhaps most Australian languages with an ergative case marker, the same element (-ingga) also functions as an instrumental case marker, which is syntactically distinguishable from the function being discussed here, on grounds developed in Rumsey (2000:52-64).
} 
(7) ngiyirri muway-yawu banga'iyirra-y-g we camp-ALL go.back'1R:RA2-PST-PL We went back to the camp/back home.
ngindaji-ingga gurama gayga'wu-ma
winthali

this-ERG man chop'FUT-3SG<3SG:MA2 firewood

This man has to cut the firewood.
winthali-ingga biyga'nginda
thinga
fire-ERG burn'1SG<3SG:YHA:PST foot
The fire burned my foot.
nyirra-ingga bananggarra'wu-ni
that.one-ERG wife.steal'3SG $<3$ SG:WU2-PST
That one stole his wife.

Not all subjects of Bunuba bivalent verbs appear in ergative case. Textual examples of ones that do not are shown in (11) and (12).

(11) jidniy gidman yungga'winda-g-ali

Sidney Kidman send.ahead'3NSG $<3$ SG:YHA-PL-PROX

Sidney Kidman sent some[of his men and cattle] ahead in this direction.
jirali gurama gudaya'wundu-nu-ngarri
wiyi
before man tempt'3NSG<3SG:WU2-PST-CTV women
The olden-days man used to tempt women.

Moreover, not all ergative-marked arguments in Bunuba occur with bivalent verbs. Some of them occur instead with monovalent verbs, often ones that have one of a series of optional oblique pronominal suffixes on the verb. Examples are (13)-(18).

(13) nyirraji-ingga baga'ra-nganggi this.one-ERG sleep'3SG:RA:PRS-2sgOBL

This one is sleeping with your wife (lit. sleeping, affecting you).

(14) wariyga'waniy-nhingi gayangurru-ingga

start.out'3SG:WU:PST-3SG.OBL echidna-ERG

The echidna started out towards to him.

niy-ingga wad'ja-y-ngarri-nhingi mamu-yawu

the.former-ERG come'3SG:RA-PST-CTV-3SG.OBL corpse-ALL

$\mathrm{He}$ (previously mentioned) came to the corpse.

$$
\begin{aligned}
& \text { mamu-ingga birayga'ra-y-nhi muway-u } \\
& \text { devil.spirit-ERG arrive'3SG:RA-PST-3SG.OBL camp-DAT } \\
& \text { The devil spirit reached/arrived at his camp. }
\end{aligned}
$$

(17) ngala-ingga gurama baljuwan.ga'waniy-nhi-ngarri

different-ERG man get.behind'3SG:WA:PST-3SG.OBL-CTV

A different man would get behind her.

$$
\begin{aligned}
& \text { nyaga'wu-ni-nya-ingga gurama gamanba'ra-y-nhi } \\
& \text { spear'3SG }<3 \text { SG:WU2-PST-SUB-ERG man look.for'3SG:RA-PST-3SG.OBL } \\
& \text { The man who speared him looked around for him. }
\end{aligned}
$$

$$
\begin{aligned}
& \text { thuthulu-ingga birayga'ra-y-nhingi } \\
& \text { pheasant.coucal-ERG arrive'RA-PST-3SG.OBL } \\
& \text { Pheasant coucal came up to him. }
\end{aligned}
$$


In terms of Hopper and Thompson's criterion of 'affectedness' of the object, all of (13)-(19) are clearly lower in transitivity than (8)-(10), where the ergative-marked NP occurs with a bivalent verb. Both sets of examples are typical in this respect: clauses with bivalent verbs tend to be higher in transitivity than those with monovalent ones, even where the latter are accompanied by oblique pronominal suffixes and/or ergative-marked subjects. The same is true in Gooniyandi, leading McGregor to categorize such clauses as a distinct 'middle' type (McGregor, 1990, 1992). But within the range of transitivity displayed by clauses with monovalent verbs and overt NP subjects, there is a further division between those with ergative marking and those without it such as (5)-(7). These are of higher and lower transitivity respectively, insofar as those with ergative marking implicate a second object-like participant that ranks relatively highly in terms of Hopper and Thompson's other object property: individuation (definiteness and referentiality). The contrast between (13)-(19) and (5) is obvious in this respect, since in (5) there is no second participant. But (13)-(19) also contrast with (6) and (7), since in all of the former the oblique pronominal suffixes make definite reference to a participant whose identity has been established earlier in the discourse, whereas this it not true either of mayi 'food' in (6) or muwe 'camp' in (7).

Occasionally an ergative-marked subject occurs with a monovalent verb which, unlike (13)-(19), does not have an oblique pronominal suffix. A textual example is (20).

mana-way-ingga wad'ja-y-ngarri ngaya'bina-gi-ngarri

elder.brother-his-ERG go/come'3SG:RA-PST-CTV ask'3NSG<3SG:RA2:PST-PL-CTV

His elder brother would go and ask all of them (for food).

Consistent with Haviland's (1979:155) analysis of similar cases in Guugu Yimidhirr under the rubric of 'ergative hopping', it seems reasonable to interpret the ergative case marking here as anticipating the bivalent verb ngaya $(g)$ 'ask' and thereby linking the action of 'going' to it as a necessary prelude to the asking.

Another example of an ergative-marked subject occurring with a monovalent verb which does not have an oblique pronominal suffix is (21).

$$
\begin{aligned}
& \text { niy-ingga wad'ja-y } \\
& \text { the.former-ERG go/come'3SG:RA-PST } \\
& \text { He (previously mentioned) approached. }
\end{aligned}
$$

This sentence comes from a story in which Emu is deprived of food while all the other birds are allowed to eat. The presence of the ergative marker on niy 'the former', which refers to Emu, can be related to the givenness of the food as a highly salient goal towards which Emu's movement is directed. It is also relevant to consider what comes immediately after (21) in the story, namely two clauses which translate as: (21a) 'He went down to the river' (21b) 'He ate it'. Within the sequence of (21)-(21a)-(21b) as a whole, the ergative marker in (21) may perhaps be understood both as the marker of agency in an implicit act of taking, and as an 'anticipatory' ergative marker for the subject of (21b) (an extended version of Haviland's 'ergative hopping') especially given that there is no other intervening NP after (21) referring to the same participant. In any case, the food which is the object of the verb in (21b), as a key participant in the story remains given or recoverable as a referent without any overt NP referring to it in that clause, just as our understanding of line (21) can presuppose it as Emu's implicit goal (for further details concerning this example, see Rumsey, 1994:143).

Exceptions such as (11)-(21) are rare. On the whole, there is a very close correlation between ergative-marked NPs and cross-reference in bivalent-subject position, and an even closer one between non-case-marked NPs and crossreference in monovalent-subject position. In a textual sample of 210 clauses with bivalent verbs and overt NP subjects, 186, or approximately $89 \%$ had ergative-marked subject NPs. And in a textual sample of 103 clauses with NP subjects and monovalent verbs - excluding for now those which serve to frame reported speech - there were only two with ergative-marked subjects. The other 101, or ca. $98 \%$ of them, had non-case-marked subjects.

Besides object individuation, what other factors might be relevant for the use of the ergative marker in Bunuba? One referee has rightly pointed out that one of them might be verbal aspect, which is another dimension of contrast that Hopper and Thompson found to be relevant for clause-level transitivity - punctual and telic aspects being associated with high transitivity and non-punctional and atelic with low. In Bunuba there are two relevant categories of this kind: continuative aspect, marked by the suffix -ngarri versus (formally and functionally) unmarked aspect 
(see Rumsey, 2000:97); and inherent lexical aspect (Aktionsart), marked by the choice of telic versus atelic verb roots (see Rumsey, 2000:76-77). Regarding continuative aspect, there is a correlation of the expected kind, but only a weak one: among the 13 non-ergative-marked subject NPs in a sample of 75 clauses with bivalent verbs, the verb was continuative-marked in 10 of those clauses, i.e., ca. $77 \%$, whereas the incidence of continuative marking for the sample as a whole was $44 / 75$ or ca. $59 \%$. While suggestive, this difference is not statistically significant given the sample size. Applying the chi square test to these figure yields a value 1.782 with 1 degree of freedom, and a two-tailed $P$ value of 0.1819 , well above the conventional .05 threshold for statistical significance.

Regarding lexical aspect, in the same sample there was virtually no correlation with subject case marking: among the 36 clauses with telic roots, 30 had ergative-marked subjects and 6 had non-ergative-marked ones, while among the 39 clauses with atelic roots, 33 had ergative-marked subjects and 6 had non-ergative-marked ones. Nor was there any significant correlation between subject case-marking and tense or mood. ${ }^{5}$

Another possible factor relating to verb semantics and/or the situated meanings of verbs in particular clauses is the degree of volitionality and/or control exercised by the referent of its subject NP. These factors are worth considering in light of the role that they have been found to play elsewhere in the differential case of marking of both 'split intransitive' (or 'split-S') languages (Mithun, 1991; Foley, 2005) and 'ergative' or OEM types (Anderson and Wade, 1988; McGregor, 1992:285; see also McGregor, this issue). While these factors may sometimes play a part in the use of ergative marking in Bunuba, it cannot be a major one. For, at least in the case of bivalent verbs, neither volitionality nor control is either a necessary or sufficient condition for ergative-marking on the subject of bivalent verbs. That it is not a sufficient one is illustrated by (11) and (12), both of which involve a volitional, controlling subject which appears in bare form rather than with the ergative marker. This also applies to other clauses without ergative-marked subjects in the sample, with verbs like 'give', 'hook up', 'look at', 'follow', 'bother', 'tell to', 'cook', 'eat', 'put down', 'throw', 'cut up', 'lift up' and 'get'. That volitionality or control is not a necessary condition is shown by the fact that subjects of non-volitional predicates, non-controlling experiential bivalent verbs such as 'hear' and 'see' regularly appear in the ergative case, as do inanimate subjects of verbs such as 'burn', as in (9). For monovalent verbs too, it is clear that neither volition nor control is a sufficient condition for ergative marking on the subject, as shown by (6) and (7), and, indeed, by the majority of the clauses in my sample with monovalent verbs (e.g., come, go, camp, sit down, fly away, play, stand up, walk around, return, wade, talk, climb up, work, stay away, run). It is harder to determine whether volition or control is a necessary condition for ergative-marking on the subjects of monovalent verbs, since it is used so infrequently in any of them except the ones that frame reported speech, which by nature all involve volitional, controlling subjects. In any case, the point is almost moot, since, as we shall see in section 4 the vast majority of monovalent clauses that have ergative-marked subjects are ones that frame reported speech, where the variable occurrence of ergative case marking, if it is serving any function at all must be indicating something other than volitionality or control.

Finally, especially in view of McGregor's (1992) findings concerning OEM in the neighbouring language Gooniyandi, it is worth considering whether ergative marking in Bunuba might in a least some contexts be used, not just to mark agency, but to foreground the agency being attributed to the referent of the NP on which it occurs (see also McGregor, this issue). I would not exclude this possibility in Bunuba; indeed I have found some instances of ergative marking in the texts which are amenable to that interpretation (see note 8). But, as McGregor acknowledges, it is difficult in most contexts to adduce objective evidence for such a function since "it relates to grounding relationships, which cannot be observed in discourse substance - independent, that is, of the targeted morpheme, the ergative postposition" (McGregor, 1992:278). While I think that more interpretative methods of the kind used by McGregor can be illuminating, and that his article amply demonstrates this (like McGregor, 1998, 2006), in order to provide evidence on this question that can be related to other aspects of my argument, including the comparison with Ku Waru below, I have focused on a single dimension of contrast that can easily be quantified, namely, subject continuity. Assuming that, other things being equal, subjects of bivalent verbs (most of which are notional agents) are more likely to be foregrounded when they are different from the subject of the verb in the previous clause, I have asked whether

\footnotetext{
${ }^{5}$ Among the 75 clauses in the (largely narrative) sample, the verbs in 72 of them were in the past indicative. The subjects in 60 of those clauses were ergative marked, while the subjects in 12 were non-ergative marked. The verbs in the other three clauses were in the present indicative, future and future irrealis. The subjects in all of those clauses were non-ergative-marked. While the latter fact is interesting, the sample is far too small to draw any firm conclusions without further study. (In other Bunuba material I have recorded, ergative case marking is attested in every tense-mood category including present indicative, future and future irrealis.)
} 
they appear with ergative case marking under those conditions more often than when the subject stays the same from one clause to the next. In my sample of 75 bivalent clauses with subject NPs I found that the referents of 56 of them were different (or at least partially disjunct) from that of the previous clause, and were the same in the other 19. Within the set of 56 clauses where they were different, ergative marking was found on 45 of the subject NPs, or approximately $80 \%$. Within the set of 19 clauses in which the subject was the same as in the previous clauses, ergative marking was found on 15, or approximately $79 \%$. From this distribution I conclude that, while the Bunuba ergative marker may serve a foregrounding function in some contexts, the patterns of subject continuity versus discontinuity in my sample provide no evidence for it.

To sum up this discussion of ergative marking in Bunuba, five kinds of possible functional correlates have been considered: object individuation, object affectedness, verbal aspect, subject volitionality or control, and the foregrounding of agent NPs in discourse. Little or no evidence was found for any of the last three, but considerable evidence was found for the first two. Especially telling in this regard was the distribution of ergative marking on monovalent verbs, which is always associated with the presence of a second participant which is a notional patient or goal, sometimes given only in the discourse context, but most often also by oblique pronominal cross-reference on the verb. And within the range of clauses which meet that necessary condition for ergative-marking on the subject, the ones in which it occurs tend to be ones with relatively highly individuated and/or highly affected objects.

Given patterns such as these, in what sense can ergative marking in Bunuba be described as 'optional'? Certainly not in the sense of 'facultative', or 'in free variation with zero case marking'. Rather, it is optional in the sense of not being entirely determined by the valence of the verb with which the relevant NP occurs - unlike in Dyirbal, for example, where according to Dixon (1972), any common noun that occurs as the subject of a transitive verb must be marked for ergative case. In Bunuba by contrast, the choice of ergative versus zero case marking is, in at least some syntactic environments an independently meaningful choice which conveys positive semantic and/or pragmatic information about the NP or the clause in which it occurs. While the precise nature of that information is context specific, it seems to me that much of it can be understood in terms of the framework inspired by Hopper and Thompson (1980) that I have adduced above - especially if we treat syntactic and pragmatic features entailed by that framework not as entirely independent conditioning factors which are there in the context per se, but as values which are realized in part by the case marking itself (see further Rumsey, 1994:150-151; McGregor, 1994, 1997).

\section{Bunuba reported speech}

All clauses which frame reported speech in Bunuba make use of the monovalent verb MA, 'say', 'do'. ${ }^{6}$ As exemplified by (1) and (2), when these clauses include NP subjects, they sometimes occur with an ergative case marker and sometimes without, as is true of the other monovalent clauses discussed in section 3. But there is a striking contrast in the incidence of ergative case marking as between the clauses which frame reported speech and all other ones with monovalent verbs (including MA in other functions besides the framing of reported speech). In order to show this, the sample of monovalent clauses that I used in section 3 did not include any clauses of the former sort. On that basis, recall that the subject NPs in only $2 / 103$ or about $2 \%$ were ergative-marked. By contrast, in a sample of 64 clauses in which MA is used to frame reported speech, 43 or ca. $67 \%$ had ergative case making - a difference of approximately 34 to 1 . In this section, while drawing upon some of the conclusions in section 3 regarding other monovalent clauses, I will be dealing exclusively with MA clauses which frame reported speech, comparing the ones that have ergativemarked subjects versus non-ergative-marked ones, and trying to establish the functional difference between them in this particular syntactic environment. First I will provide some further details and examples of the MA clauses which frame reported speech. Besides (1) and (2), some further examples are (22)-(26). The framed material is shown in italics.

\footnotetext{
${ }^{6}$ This verb root functions as one of the ten inflecting verbs used in Bunuba complex verbs, and is textually quite frequent in that function. However, unlike almost all the other Bunuba verb roots, it is also used without an accompanying preverb. When this happens, in the vast majority of instances, it is being used to frame reported speech or thought. Occasionally it is also used without an accompanying framed locution to mean 'do' or 'be the case'. As far as I know it is never used by itself to mean 'speak', 'talk' (for which there are other, complex verbs, which, however, are not used to frame reported speech).
} 


$$
\text { wilagurru mi-y-birrangi gananganja-ingga nginjaga }
$$

alright 3SG:say-PST-3PL.OBL emu-ERG what.

nga'gunggura-ngarri mamulgu

eat'PRS:3SG $<2$ NSG:RA2-CTV secret/sacred thing

"Alright", said the emu to them, "what's that secret/sacred thing that you(pl.) are eating?"

$$
\text { nginji-ingga wilama wad'ginja mi-y-nhingi gayangurru-ingga }
$$

you(SG)-ERG all take'PRS:3SG $<2$ SG:RA2 3SG:say-PST-3SG.OBL echidna-ERG

"You are taking all of it" the echidna said to him.

$$
\text { mila'w-a jiyirrmi-y-g ngindayani mayi }
$$

look'FUT-2SG>3SG:RA2 1R:say-PST-PL these bush.food

"Look at this" we said, "these are bush foods".

$$
\text { garrga-yarra'wanbuni mi-y }
$$

leave-maybe'FUT:1U<3SG:WU2 3SG:say-PAST

$\mathrm{He}_{\mathrm{i}}$ said he $\mathrm{j}_{\mathrm{j}}$ might leave us.

$$
\begin{aligned}
& \text { yaninga ngayaga'w-arrma limi-y-birrangi } \\
& \text { now ask'FUT-1U>3SG:MA2 } 1 \text { SG:MA-PST-3PL.OBL } \\
& \text { "We have to ask him now" I said to them. }
\end{aligned}
$$

Sometimes the words framed by MA are understood not as actual speech, but as thought or intention. So for example (25) could in some circumstances be used to mean 'He thought he might be leaving us'. In Bunuba as in the neighbouring language Ungarinyin (Rumsey, 1982:157-166, 1990) these framing constructions are in fact the standard way of attributing intentions, which are represented as a kind of 'inner speech'. Further examples are (27) and (28).

$$
\text { nginji-guda wurrba'wuni gima-nganggi }
$$

you-COM sit.down'FUT:3SG:WU 3SG:say/do-2SG.OBL

He wants him to sit down with you (literally: $\mathrm{He}_{\mathrm{i}}$ is doing/saying with regard to you: "he $\mathrm{j}_{\mathrm{j}}$ should sit down with you".)
jagarra mi-y-ngarragi
wad'b-irra jibirri ngurru yanarri-yawu
Jagarra SG:say/do-PST-1SG.OBL go'FUT-1R:RA west there town-ALL
Jagarra wanted me and him to go over there to town. (lit.: "said/did "we two should go..." ").

Note that in (27) the oblique pronominal suffix on the framing verb refers to the person whom the framed locution is about, whereas in (22), (23) and (26) it refers to the addressee of the act of speaking predicated by that verb. Where the framed material is inner thought, the latter interpretation is ruled out. Where it is actual speech, the oblique suffix sometimes refers to the person or thing that the locution is about, but more often refers to the addressee.

As shown in Rumsey (1994), ergative case marking on the subject of MA clauses such as those found among (22)-(28) is positively correlated with: (i) explicit reference in the same clause to an addressee; (ii) the presence of a framed locution which is relatively highly individuated as a single discrete speech event. Where condition (i) is met, the object properties of both the addressee (as a more-or-less individuated one) and of the framed locution figure in the overall transitivity status of the framing clause. In order to study the properties of the framed locution as an independent variable, I assembled from texts a sample of sentences in which there was an overt NP subject but no addressee NP. These are shown in 29 and 30 (which I give in English translation only, with an indication of where the subject in the Bunuba framing clause occurred in ergative case versus without it). These 18 sentences comprise a representative sample with respect to the phenomena in question, in that they are all the instances of the MA construction that I found in a textual corpus of some 2000 lines of text which (i) include an overt NP subject in the framing clause, and (ii) do not contain an oblique pronominal suffix on the verb referring to an addressee. The latter restriction is a necessary one for this purpose because, as explained above, the presence of such a suffix is itself positively correlated with ergative marking on the subject.

(29a) White people[ø] call it (literally: 'say') 'Hooper's Creek'.

(29b) This man[ø] wants to sit down (literally: 'says/does "I'll sit down",').

(29c) The black cockatoo[ø] says/goes[CTV] 'burrij burrij'. 
(29d) The police[ø] thought he (Pigeon) was bad (lit.: "said[CTV]"bad" ').

(29e) Lawandi got ready to get up (lit.: "said "I will get up" ').

(29f) "What about me?" said Emu[ø].

(29g) He[ø] said[CTV] "all right".

(29h) Now we all[ø] say "nalija" (for 'tea').

(29i) Nightbird[ø] started saying/going "juwag juwag".

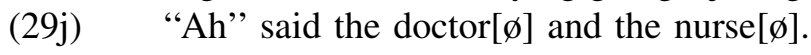

(30a) This man[-ERG] says he wants to sit with that man.

(30b) In Bunuba we[-ERG] say barramundi is of the Jawandi subsection.

(30c) "Just you wait; one day you'll see" said [CTV] her husband[-ERG].

(30d) "Come and get this; it's your food" he[-ERG] said.

(30e) "What about me?" said Emu[-ERG].

(30f) "Where is he? There's no food. He took it away from me. There's no food.

He took it away from me" said the dove[-ERG].

(30g) "He's still standing up there", said the big mob of people[-ERG].

(30h) "They use this one [for cooking]. They gave it to us --- flour" said the old people [ERG].

While this is for some purposes too small a sample from which to generalize, there is one conclusion that it strongly supports, namely, that at least some instances of reported speech are treated like a grammatical object. For in 8/18 or $44 \%$ of these examples (30a-h), the subject of MA takes an ergative marker. And as I have shown above, in other kinds of clauses this is always correlated with the presence of second, object-like participant in the action or process that is predicated by the verb. I would maintain that in all of these instances, the framed locution comprises just such a 'participant'. To label it in that way is cumbersome, but in fact the relation between a reported locution and its framing verb is readily recognizable in the some of the same terms that grammarians have applied to the semantics of object arguments of the more usual sort. Perhaps the most perspicuous of them for this purpose is Charles Fillmore's notion of the 'Factitive', which is "the ['deep'] case of the object or being resulting from the action or state identified by the verb, or understood as a part of the meaning of the verb" (Fillmore, 1968:25). Although this concept has not often been applied to reported speech (see however Hopper, 1985:73-74), it seems highly applicable, since a reported locution is that which results from the action of saying which is predicated by the framing verb. Hence the treatment of it as a grammatical-object-like participant in Bunuba, as indicated by the ergative marker on the subject NP.

Why, then, does the ergative marker not always occur on the subjects of such clauses, as shown by (29a-j)? I submit that the differences in this respect between $(29 \mathrm{a}-\mathrm{j})$ and $(30 \mathrm{a}-\mathrm{h})$ can be understood largely in terms of analogous principles to those that I drew on above when discussing the difference between (6)-(7) and (18)-(21). In both cases, the relevant concept from Hopper and Thompson (1980) is that of object individuation. But whereas, in the case of nominal objects the relevant dimensions of individuation are definiteness and referentiality, in the case of reported speech ones the relevant variable is the extent to which the framed material is a more-or-less extended locution, the uttering of which is being focused on as a discrete speech event within the narrative frame. Thus, almost all the examples in (30) are more lengthy utterances than those in (29). In at least four of the non-ergatively framed examples (29a), (29c), (29d) and (29h), the framed material is not an utterance token at all, but an utterance type, which is characteristically or generically associated with a specified class of 'speaker'. In two more of those examples (29b, 29e), the framed 'event' is a discrete one but is not focused on as an utterance event. Rather, in these examples as in (26) and (27), sentences which are formally identical to reported speech are being used to represent mental states, intentions.

Not all of the variation in these examples can be explained according to properties of the framed locution. A major exception is (29f) versus (30e), which are identical except for the presence of the ergative marker in the latter. ${ }^{7}$ But

\footnotetext{
${ }^{7}$ Nor does it seem apparent how this instance could be explained in terms of McGregor's (1992) analysis of ergative making in the neighbouring language Gooniyandi which explains it according a single principle of foregrounding versus backgrounding of agency, since the discourse environments for these two clauses are nearly identical, coming as they do from parallel positions within two repetitions of a single narrative sequence in which all the other animals besides Emu are given food, while he keeps being told to wait for his. Of course one can always take the presence of the ergative marker alone as sufficient evidence for "the intentionality of the signer" (McGregor, 1992:278) with respect to foregrounding but I prefer to rely more exclusively on formal evidence of the kind that I have drawn upon here - rates of use of ergative case marking in given syntactic and textual environments, etc. (which McGregor's analysis also draws upon to a considerable extent).
} 
Table 1

Some Ku Waru compositional verb constructions with nyi-, 'say'/'speak'.

\begin{tabular}{lll}
\hline yi- pilyi- & say/speak + hear & 'think, believe' \\
nyi- modu- & say/speak + send & 'relay news (about)' \\
nyi- si- & say/speak + give & 'report, tell to' \\
kodu- nyi- & pull + say/speak & 'refer to', 'mention' \\
(ung) nyi- pensi- & (word) say/speak + put & 'propose' \\
pilyi- nyi- & hear + say/speak & 'speak informedly (about) \\
pilyi- kongunsi- nyi- & hear + work-CSV + say/speak & 'deliberate about' \\
\hline
\end{tabular}

overall there is a high degree of correspondence between the case marking of the subject of speaking and the discreteness of the framed locution as utterance event, allowing us to rank instances of the MA construction for 'transitivity' in such a way as to make sense of the variation between ergative and absolutive case-marking for their subjects.

Before leaving Bunuba it is worth noting that the association between ergative case marking and the subjects of framing clauses is so well established that an ergative-marked NP alone can serve that function even in the absence of a verb. Examples are:

$$
\begin{aligned}
& \text { niy-ingga ngay ngag'w-ula nyana } \\
& \text { he-ERG not eat'FUT-1SG:RA much } \\
& \text { He (said) "I won't eat much" } \\
& \text { gurama-ingga wangaja } \\
& \text { Aborigines-ERG Wangaja } \\
& \text { Aborigines (say/call it) Wangaja. }
\end{aligned}
$$

(32) could be taken as an example of verbal ellipsis, as it was immediately preceded by (29a) which does have a framing verb gurrma 'they say', the sequence being glossable as 'White people call it Hooper's Creek, Aborigines Wangaja'. No such antecedent is present as a basis for ellipsis in the case of (31), which is preceded by reported speech from another character in the story, who says "You leave some for your cousin, the dove".

\section{Ku Waru clause types and OEM}

Like many other Papuan languages Ku Waru is a rigorously verb-final one: the main verb in the clause always comes last. There is a small stock of verb roots which are strung together in serial combinations to yield more-or-less idiomatic meanings of a kind which in other languages are expressed by a single verb: 'get' + 'carry' + 'go' = 'take', 'get' + 'carry' + 'come' = 'bring', etc. (see Table 1 for further examples). This is facilitated by an extensive system of verb chaining using the so-called 'medial' or 'non-final' verbs, which are non-finite in that they do not inflect for tense, but for same-or-different subject, temporal sequencing, etc.

There is a problem with trying to apply ergative/accusative typologies to Ku Waru insofar as these presuppose a basic division of verbs and/or clauses into transitive and intransitive ones. In English and many other languages, there is a fundamental division between intransitive verbs and transitive ones, and a more-or-less clear cut distinction between corresponding clause types: intransitive ones, involving a single core syntactic case role, and transitive ones, involving two, one for the agent of the action and one for the undergoer or patient. We have seen that in Bunuba this alignment is somewhat problematical in that the distinction between monovalent verbs (with pronominal prefixes cross-referencing a single argument) and bivalent verbs (with prefixes for two of them) does not correspond completely to differences of transitivity that can be discerned at the clause level. But the problems with such a

\footnotetext{
${ }^{8}$ This clause comes from the same text as do (29f) and (30e), as discussed in the previous note, $n i$ 'he' in this clause referring to Emu, the main character in the story. In this case McGregor's analysis in terms of the foregrounding of agency seems quite applicable, given the shift in the role of Agent from those distributing the food to Emu, to whom they are denying it. McGregor's analysis of Gooniyandi texts shows this kind of shift to be correlated with ergative case marking. Similar considerations also apply in the case of (32), where the agency of whites and Aborigines is arguably being contrasted.
} 
two-way distinction are even greater for Ku Waru because its verb morphology provides no basis for such a binary classification, and because the majority of Ku Waru verbs can occur in construction with either one or two NPs in core syntactic roles as marked by various combinations of verb agreement, normal word order and the possibility of occurrence without a case postposition, or with the one which, for reasons to be discussed below, we regard as an ergative marker, $-n(i){ }^{9}$

Examples of verbs in clauses with a single argument are:

ab dau taiki te-pa pu-ly-m

woman Dau always do-NF:3SG go-HAB-3SG

[The woman called] Dau always goes.

(34) na kol-ku-r

I die-PPR-1SG

I am dying.

eni yi-ma ya pilyi-k kana-k te-angi

you(PL) man-PL here listen/hear-NF:2/3PL see/watch-NF:2/3PL do-HRT:2/3PL

You men here, listen and watch.

(36) angbu-yl kapu le-ki-m

kunai-DEF dry be-PPR-3SG

The Kunai grass is (getting) dry.

ab-ayl pu-pa yunu-nga kolya molu-r-um

woman-DEF go-NF:3SG he/she-GEN place stay/be-RP-3SG

The woman went home to her place and stayed there.

Examples of verbs in clauses with two arguments are:

$$
\text { na-n kera laima-yl to-p konsu-d }
$$

I-ERG bird cassowary-DEF hit-NF:1 die:CAUS-PRF:1SG

I killed the cassowary.

meri kang-ayl ab-ayl eni-ni tukud lyi-ngl

down boy-DEF woman-DEF you(PL)-ERG inside take-PRF:2DU

Down there you two took the boy and the woman in.

40) ab ilyi-ni olyo kep faul te-ki-m

woman this-ERG we also wrong do-PPR-3SG

This women is doing us wrong too.

ab-ayl eni-ni me-k sukud pu-k kot te-ang

women-DEF you(PL)-ERG take-NF:PL inside go-NF:PL court do-HRT:2/3PL

You(pl) should take the woman inside and try her.

lku suku pi nabolka mel olyo-n mel-ma ko bo lyi-mulu-i

house inside then what thing we-ERG thing-PL so plant get-FUT:1PL-Q

What kind of crops can we raise inside the house?

As in Bunuba, when Ku Waru sentences such as (38)-(42) are elicited in isolation, speakers almost always include the ergative marker on the subject NP. But in less self-conscious, connected speech, two-argument clauses are often found with subject NPs that are not ergatively marked. In order to be able to ground the analysis of such phenomena in connected speech, as in a previous publication (Merlan and Rumsey, 2001), almost all the examples used in the rest of

\footnotetext{
${ }^{9}$ As in many other languages with an ergative marker (including Bunuba as discussed in note 4), this marker in Ku Waru is homophonous with an instrumental marker, from which it may be distinguished on syntactic grounds as discussed in Merlan and Rumsey (1991:337-343).
} 
this article have been taken from a 1744-line transcript of a public, multi-participant paternity dispute that Francesca Merlan and I recorded in 1983 as part of a study of the conduct of public speech events among Ku Waru people. Since that full transcript has been published elsewhere (Merlan and Rumsey, 1986:86-179) the data are available for inspection by interested readers. ${ }^{10}$ Examples from the transcript of transitive clauses with non-ergative-marked subjects are:

$$
\begin{array}{lll}
\text { Kujilyi ung } \quad \text { mim } & \text { te-ly-m } \\
\text { (man's name) } & \text { speech/words fix/fabricate do-HAB-3SG }
\end{array}
$$
Kujilyi makes up things/tells tall tales.

(44) ekapu olyo ing-te naa nyi-molu now we word-IDF not say/speak-FUT:1PL Now we won't say anything.

$$
\text { mola nu aku-na yabu-ri to- konsi-ki-n }
$$
or you that-LOC person-IDF hit die:CAUS-PPR-2SG Or is this a case of your having killed someone?

(46) nu mong lyi-n

you trouble get-PRF:2SG

You've gotten in trouble.

The following, more extended example, comes from a point in the dispute where there is a discussion of how people tend to inherit the behavioral characteristics of their parents. It includes three two-argument clauses in sequence, each with a non-ergative-marked subject.
(a) yabu-nga eni-nga memi-na kilyi [kung gai punya no-ly-m] people-GEN they-GEN blood-LOC because pig sweet.potato garden eat-HAB-3SG
(b) [kalya kung gai punya no-ly-m] like.that pig sweet.potato garden eat-HAB-3SG
(c) [pe yabu pudu lyi-ly-meli] kalyayl pudu lyi-ly-meli-kily so people trouble get-HAB-3PL like.that trouble get-HAB-3SG-thus

It is because of what is in people's blood. If a pig eats sweet potato gardens, his offspring will also eat sweet potato gardens. In the same way, the offspring of people who get into trouble will also get into trouble.

In a sample of 118 two-argument clauses from which most of the above examples are taken, the subject NP was ergative-marked in 73 , or approximately $62 \%$, and unmarked in 45 , or approximately $38 \%$ of them. How are we to account for the difference? Here again, a range of possible factors suggests themselves along much the same lines followed out for Bunuba in section 3.

First, there are the parameters of subject volitionality and control, which have a special relevance here in view of findings concerning the Papuan language Folopa by Anderson and Wade (1988), who argue that the choice of ergative versus absolutive marking for subjects of both transitive and intransitive verbs "is dependent on the amount of control attributed to the subject" (14). Here again, as in the Bunuba case, a comparison between the verbs in the clauses with ergative-marked versus non-ergative-marked subjects, and their uses in context, reveals little if any systematic covariation in this respect, with many verbs occurring in both environments, seemingly without much regard for differences of control or volition. Among the seven clauses in (43)-(47), for example, all but two, (46) and (47c), seem to entail control on the part of the subject even though it is not ergative-marked.

To provide fuller quantitative evidence on this matter I examined all 118 clauses in the transitive clause sample within their discourse contexts and did a rough three-way classification of them as involving a high degree of

\footnotetext{
${ }^{10}$ To make it easy to locate each of the examples used here within the published text in Merlan and Rumsey (1986), to the right of each example in square brackets I give the line number in the transcript from which it comes. For readers who wish to search for other examples of ergative marking in that transcript, instances of it are easily locatable there because it always appears with a hyphen (as -ni or $-n$ ).
} 
control on the part of the subject, a low degree, or an indeterminate one. Among the 73 clauses in the sample with ergative-marked subjects, I judged 49 , or approximately $67 \%$ of them as involving a high degree of control on the part of the subject, 13 or approximately $18 \%$ as involving little or no control, and 11 or approximately $15 \%$ as indeterminate. Among the 45 clauses in the sample with non-ergative-marked subjects, I judged 26, or approximately 58\% as involving a high degree of control, 6 or approximately $13 \%$ as involving little or no control, and 13 or approximately $29 \%$ as indeterminate. In other words, the ratio of high versus low control was nearly the same for ergative-marked agents as for non-ergative-marked ones: $67 \% / 18 \%$ versus $58 \% / 13 \%$ respectively, or approximately $3.7-1$ versus $4.5-1 .^{11}$

The second possibility to be considered is that the presence or absence of ergative marking on the subject may relate to tense-aspect-mood categories of the verb, the prototypically 'transitive' (and therefore ergative-marking) scenario being associated with past tense, perfective aspect and indicative mood, as opposed to future, imperfective and irrealis. Again, a breakdown of the sample in those terms reveals little or no systematic correlation with the relative frequency of subjects with ergative versus non-ergative case marking. The numbers of ergative-marked subjects found in construction with verbs of each category were: Present Progressive 12, Perfective 4, Remote Past 16, Future 18, Habitual 9, Optative 3, Subjunctive 1, Non Final 10. The numbers of non-ergative-marked subjects found with each were: Present Progressive 5, Perfective 4, Remote Past 9, Future 9, Habitual 11, Optative 1, Subjunctive 1, Non Final 5.

A third possibility is suggested by Hopper and Thompson's findings concerning object individuation, as applied to Bunuba in section 3. As discussed there, this parameter has two components: definiteness and referentiality. In the case of $\mathrm{Ku}$ Waru there is good formal evidence that can be used for establishing the former, since the language has a definite marker that occurs on (third person, lexical) NPs of all sorts. Examples may be found in (4), (38), (39) and (41). Note that the definite marker occurs on the object NP in three of the five sentences among (38)-(42) (i.e., on three of the five clauses that have ergative-marked subjects) and on none of (43)-(47) (i.e., on none of the seven clauses that have nonergative-marked subjects). This reflects a general tendency throughout the textual corpus for two-argument, transitive clauses that have definite-marked object NPs to show a greater incidence of ergative-marked subjects than do the clauses with NP objects which are not definite-marked. ${ }^{12}$ Within the sample of 70 transitive clauses with ergativemarked subjects, 21 , or $30 \%$ of them have definite-marked objects, whereas within the sample of 45 transitive clauses with non-ergative-marked subjects 6 , or approximately $13 \%$ have definite-marked objects.

The picture provided by these figures, while revealing in itself, is only a partial one, in part because definite marking occurs only on third person, lexical NPs, and not on pronouns. But first and second person pronouns are, in functional terms, obviously highly individuated - more so even than definite-marked lexical nouns, as their reference in any given instance is indexically anchored in the act of speaking in which they are used (cf. Silverstein, 1981, 2003 and Merlan and Rumsey, 2001:229-230 on 'metapragmatic transparency'). Thus, the incidence of ergative-marked subjects with personal pronouns as objects can provide further evidence for a relationship between ergative marking and object individuation. Within the sample of 70 transitive clauses with ergative-marked subjects, 9 or approximately $13 \%$ of them have first or second person pronouns as objects, whereas within the sample of 45 transitive clauses with nonergative-marked subjects 2, or approximately $4 \%$ have first or second person pronouns as objects. While the smaller sample size for pronouns makes this finding less significant than the one regarding definite-marking for NPs, if we

\footnotetext{
${ }^{11}$ For anyone who wants to check my judgments in this matter, all of the data are available in the published transcript in (Merlan and Rumsey, 1986:86-179). The clauses that I have categorized in each of the six ways reported above may be found in the following numbered lines of that transcript: volitional clauses with ergative marked subjects: 146, 168, 206, 215, 310, 400, 401, 435, 472, 488, 608, 709, 770, 812, 813, 868, 902, 903, $915,932,942,953,964,968,978,999,1016,1042,1046,1125,1161,1042,1046,1125,1161,1163,1174,1244,1255,1273,1342,1370,1378$, 1396, 1439, 1546, 1563, 1614, 1642, 1700(x2), 1730; non-volitional clauses with ergative marked subjects: 409, 474, 476, 589, 767, 852, 854, 855, $879,1082,1162,1164,1374 ; 3)$ volitionally indeterminate clauses with ergative marked subjects: $156,615,782,829,880,896,900,914,954,955$, 1168; volitional clauses with non-ergative marked subjects 63, 81, 186, 204, 205, 376, 477, 523, 729, 730, 793, 836, 838, 851, 896, 900, 936, 984, 1006, 1008, 1084, 1262, 1263, 1365, 1468, 1470; non-volitional clauses with non-ergative marked subjects: 507, 530, 540, 598, 730, 1089; volitionally indeterminate clauses with non-ergative marked subjects: 55, 189, 307, 456, 466, 467, 614, 694, 862, 1032, $1091,1563,1576$.

${ }^{12}$ Note that there is a near-minimal contrast in this respect between (38) and (45). The verb combination in both clauses is to- kons-, 'strike dead' ('hit'- 'die': cause), but in (38) the subject is ergative-marked, whereas in (45) it is not. This can be related to the fact that in (45) the object noun yabu 'person' not only occurs without the definite marker, but is explicitly marked as indefinite, and is non-referential. For establishing the latter, it is relevant to know that this clause was preceded by a remark from the same speaker to the effect that 'We can get through this case easily'. The point of the rhetorical question with which he follows this in (45) is that the woman he is addressing, Moni, is not being accused of killing anyone, but of the lesser offence of adultery. (For the full context see Merlan and Rumsey, 1986:113.)
} 
combine the two sorts of evidence under a single category of object individuation, they reinforce each other, increasing the total sample size and giving an aggregate figure of approximately $43 \%$ for the proportion of transitive clauses with ergative-marked subjects which have objects that are individuated in one of these two ways or the other, and approximately $18 \%$ for those with non-ergative-marked subjects. Application of the chi-square test to these figures shows that the correlation between object individuation and ergative subject marking is a statistically significant one, with two-tailed $P$ value of 0.0224 (i.e., only a $2.24 \%$ probability of finding such a large variation from the even distribution of individuated and non-individuated objects across clause types that would be expected by the null hypothesis).

Besides individuation, the other of Hopper of Thompson's object properties that may be relevant to some extent in $\mathrm{Ku}$ Waru is object 'affectedness'. This is in many textual instances associated with object individuation. For example in (47), the verb no- 'eat/drink/consume' occurs in two clauses with kung 'pig' as their subject. The absence of ergative marking on it can be related to the fact that the object of the clause, gai punya 'sweet potato garden(s)' rates low in individuation both formally (since it lacks a definite marker), and discourse-functionally, since it in this instance it does not refer to any particular garden, but to gardens in general. But even if it did refer to a particular garden, the object would still rank relatively low according to Hopper and Thompson's in terms of 'affectedness', since pigs do not eat entire gardens, but, at most, some of the sweet potatoes in them.

Finally, we need to consider as we did for Bunuba the question of whether ergative marking in Ku Waru might in at least some contexts be serving as a foregrounding device. This is especially relevant in view of the literature on similar markers in other Papuan languages in which it has been treated as a marker of 'saliency' (Potts and James, 1988) or 'focus' (contrastive or otherwise) upon the subject NPs on which it occurs (Donohue and Donohue, 1997; Donohue, 2005; San Roque, 2008:chapter 6). Since this applies both to transitive clauses and intransitive ones, and in order to show why I consider $-n(i)$ to be an ergative marker notwithstanding the fact that is used in some intransitive clauses, it is relevant here to provide some more details concerning the latter.

For reasons discussed above (and others which will become clearer below), many actually occurring clauses in $\mathrm{Ku}$ Waru are difficult to classify categorically as either transitive or intransitive. In a sample of 176 clauses with overt NP subjects from the first 500 lines of the transcript in Merlan and Rumsey (1986) which I have classified as intransitive, the subject is marked with $-n(i)$ in 21 and in the other 155 it occurs in bare form. Some examples of the latter sort are (33)-(37). Examples with ergative-marked subjects are given below, some of them with the preceding line given in translation:

We're going to hold court now;

$$
\text { eni-n ekepu pily-ai }
$$

you(PL)-ERG now listen/hear-IMP:PL

You people listen!

We won't say anything now.

(49) ya kalapura-ni aku-ru-m

here frost-ERG extract/dig.out-RP-3SG

Here the frost has already destroyed [the crops].

They acted that way and, well,

na-n ya ul ime-nga suku kot tep te-ly-o

I-ERG here thing those-GEN inside court do-NF:1 do-HAB-1SG

I hold court inside [the village court house] here about those matters.

We're putting her case on top of the agenda

eni yi-ma-n pilyi-k i nyai

you(pl) man-PL-ERG listen-NF:2/3PL this speak:IMP:PL

You men listen and talk about it.

If you had flirted on another occasion, well

[ola yiyl-n kana-pa mo(l)-ly-m] autim te-lkomola

above man-ERG see/watch-NF:3SG be/stay-HAB-3SG reveal do-SBJV:1PL

God [lit: 'the man above'] is watching; we would have revealed it [to him.] 
Before discussing these examples with respect to the question of ergative marking, some preliminary remarks are in order concerning the problem of categorizing them with respect to transitivity. Sentences (48), (51) and (52) all involve perception verbs (hear/listen, see/watch) in contexts where it is clear from the preceding sentence exactly what the entailed object of perception is meant to be. I have treated them as intransitive only because the object is not present within the same clause as the verb. In (49) there is also an understood object, but it is not explicitly present within the text per se. Rather, it is understood as a part of the meaning of this set phase in $\mathrm{Ku}$ Waru, the sense of which is something like 'the damage has already been done' - the presupposed literal reference being to crops in a garden which have been destroyed by a freeze. In (50) the issue of transitivity is complicated in another way, by the nature of the verb construction, which consists of inflected verb root te- used in combination with the word kot, which derives ultimately (via Tok Pisin) from English 'court', but functions in this context less like an argument than as a word of the kind known to Papuanists as an 'adjunct' (Foley, 1986:113-128) - a class of words which occur in combination with a small set of semantically very general verb roots, giving a lexically specific meaning to the verb complex as whole (in this case 'hold court'). But the elements that can function as adjuncts of this kind can be more-or-less noun-like, often leaving the choice somewhat indeterminate as to whether to regard them as an argument or part of the verb complex.

Of the 21/176 clauses in my 'intransitive' sample which have ergative-marked subjects, excluding for now the ones which involve the framing of reported speech, every one of them is an ambiguous or borderline case of intransitivity for similar reasons to the ones discussed in the previous paragraph. ${ }^{13}$ There is not a single one of them which lacks all trace of a second, object-like argument such as do (33), (34), (36), and (37).

Returning now to the possible role of $-n(i)$ as a foregrounding device, as in the discussion of this possibility in Bunuba in section 3, in order to be able to produce quantitative evidence on the question I have focused on the incidence of shifts of subject versus continuity of subject from clause to clause. Note that there is such a shift of subject in all of the examples I have given of 'intransitive' ergative marking above, i.e., in sentences (48)-(52). The same is true in all but one of other 16 instances of ergative-marked intransitive subjects in my sample. ${ }^{14}$ But in this respect they do not contrast significantly with non-ergative-marked intransitive subjects: in the 155 intransitive clauses in my sample where those occur, an examination of their textual environments shows that 145 , or approximately 94\% are non-coreferential with the subject of the previous clause. An examination of the transitive clauses in the sample yielded a similar result, though with a somewhat higher overall rate of subject co-referentiality. Among the transitive clauses with ergative-marked subjects, 62/73, or approximately $84 \%$ have subjects which are non-coreferential with the subject of the previous clause. Among the transitive clauses with non-ergative-marked subjects, 19/21, or approximately $90 \%$ have subjects which are non-coreferential with the subject of the previous clause. Thus the patterns of continuity versus shift of subjects in discourse provide no evidence for a 'contrastive focus' function for $-n(i)$. What they show instead is that the mere presence of a noun or pronoun subject itself is strongly correlated with a shift of subject, regardless of whether the noun or pronoun appears with an ergative case marker. Here it must be born in mind that in connected speech, overt NP subjects are present in only a small minority of clauses, reference being maintained by a combination of zero anaphora and person/number marking on the verb.

To summarize regarding the distribution of $-n(i)$, it occurs on the majority of transitive subjects in my sample (ca. 62\%), never on objects, and on only a small minority of intransitive subjects (ca. 12\%). In every case in the sample where it occurs on an intransitive subject, it is associated with a second, object-like element, either a verbal adjunct within the same clause, or a contextually given one as in examples (48)-(52). I consider these facts to be sufficient grounds for classifying $-n(i)$ as an ergative marker, albeit an 'optional' one in the sense discussed above and by McGregor (this issue). In order to account for its optionality I have considered four possible functional correlates - verb semantics, tense-aspect-mood categories, object individuation, and contrastive focus - and found that the only one that is supported by the available evidence is object individuation.

\footnotetext{
${ }^{13}$ For readers who wish to look into this further, all of the examples may be examined in their full discourse contexts within the transcript in Merlan and Rumsey (1986). The other examples occur in lines 57, 216, 219, 244, 325-6, 331, 343, and 377.

${ }^{14}$ This includes not only the clauses listed in the preceding note, but also those which involve the framing of reported speech, which are in lines 73 , $176,193,323,324,325$, and 329 .
} 


\section{(Speaker NP(-ERG) ) [framed locution] ( $i$, 'this') [Verb of Saying based on nyi-]}

Fig. 1. General formula for framing reported speech in Ku Waru.

\section{Ku Waru reported speech}

$\mathrm{Ku}$ Waru reported speech is framed with a verb -nyi 'say/speak', which agrees in person and number with its subject. In keeping with the verb-final syntax of the language, this verb always follows the material that it frames. Examples are (53)-(56). As in the Bunuba examples, the framed material is shown in italics.
ne yi-kil-n
ab eninga-yl kanakelku-k
nyi-ki-mil

[176]

there man-PL-ERG woman yours-DEF do.completely-NF:2/3PL say/speak-PPR-3PL

Those men are insisting "She's yours".

(54) lapayl-n de yupuk kapola-ko tal kapola-ko mola

father-ERG day three o.k. two o.k. or

tripela fopela ilyi mada nyi-ri-m

three four that enough say/speak-RP-3SG

The father said "Three days, that's o.k., or two or three or four is enough".

nu-n kalya tripela te-p-kin mi-ri-bul i nyi-ki-n

you-ERG that three do-NF:1-COM bear-RP-1DU this say/speak-PPR-2SG

You say "We did it three times and conceived a child".

ab-ayl-n kangabola nu-nga nyi-ki-m

woman-DEF-ERG child you-GEN say/speak-PPR-3SG

The woman says: "The child is yours".

Based on such examples, we can give a general formula for Ku Waru reported speech constructions as in Fig. 1.

The same general form is also used when the grammatical object of nyi-is not a quote, but an NP referring to a locution without specifying what is said in it. An example is (57).

olyo-n ung kare nyi-mulu-i

we-ERG word/speech some say/speak-FUT:1PL-Q

Are we going to say a few words?

This example is unusual in that, in general, when nyi- occurs without an explicit locution as its object, the subject does not occur in ergative case but in bare form. Examples are (58)-(61).
ne ung nyi-ki-m
aki-yl nu nyi-ni

[502]

there words say/speak-PPR-3SG that-DEF you say/speak-FUT:2SG

What he's saying there is just what you'll say.

na ung naa nyi-bu

I word/speech not say/speak-FUT:1SG

I won't say anything.

(60) olyo ya kot-nga kupulanum-na pilyi-p kongu-nsi-p nyi-ki-mul

we here court-GEN way-LOC hear-NF:1 work-CAUS-NF:1 say/speak-PPR-1PL

We are deliberating about the court procedure here.

(61) na nyab

I say/speak:OPT:1SG

[718]

Let me talk. 
To obtain statistical evidence on the uses of ergative case marking in such constructions, Merlan and I did text counts on the same dispute transcript that I have drawn upon in section 5. In the 1744-line transcript we found a total of 158 clauses in which the verb nyi- 'say/speak' is used with an NP subject referring to someone who speaks. In 66 of those instances, the verb was used to frame an explicit locution as in (53)-(56). In 92 of them it was used to predicate an act of speech, but without a framed locution, as exemplified by (57)-(61). We found that among clauses which framed explicit locutions, $41 / 66$, or approximately $62 \%$ had ergative making on the subject, whereas among the ones which did not frame a locution, only 21/92, or approximately $23 \%$ had ergative marking on the subject. (For a more detailed breakdown of these figures, which takes account of the person and number categories for the subject, see Merlan and Rumsey, 2001:225-226.) In other words, across its range of occurrence on NPs which are the subjects of verbs of speaking, ergative marking occurs approximately 2.7 times more often in clauses which frame a locution than it does in other clauses of saying.

So far I have been discussing these data as if the category of 'framed locutions' were a homogeneous one. Actually there is a wide range within it, of different kinds of material which are framed. In order to describe the differences among them it is necessary now to say a little more about Ku Waru compositional verb constructions, in particular those which include the verb nyi- 'say/speak'. An example can be seen in (60), which shows how the verbs pilyi- 'hear' and kongunsi- 'cause to work' combine to mean 'deliberate about'. Other examples are shown in Table 1.

Another example of a compositional construction, illustrating the first combination shown in Table 1, is (62), which shows that construction being used to frame thought as inner speech.

$$
\begin{aligned}
& \text { nu } p u-b u-d a \quad \text { nyi-k } \\
& \text { you go-FUT:1SG-perhaps say/speak-NF:2 } \\
& \text { You may think I'll go. }{ }^{15}
\end{aligned}
$$

Alternatively, as in Bunuba and in other Papuan languages (Reesink, 1993), the 'say' verb (nyi-) can be used by itself to frame inner speech. An example is (63).

$$
\text { olyo meri yi-ke ya isi-p opimi to-mulu nyi-b... }
$$

we there man-PL here do.thus-NF:1 join do-FUT:1PL say/speak-NF:1

We, intending to join with those men here like this... [lit: 'saying "we will join with those men..." ']

These examples are intermediate between ones like (54) and (59) because although they do involve framed locutions (as shown in italics), those do not represent discrete utterances but thoughts or intentional states. In other words, here as in Bunuba, one can see that there are differences among kinds of framed material in the extent to which the reported locution is focused on as a discrete speech event - differences that can be comprehended under my extended version of Hopper and Thompson's notion of 'individuation', where this is treated as a property, not of NPs or the presumed entities that they refer to, but of reported speech in relation to the speech event in which is being reported. And in $\mathrm{Ku}$ Waru just as in Bunuba these differences of individuation (in the extended sense) tend to be correlated with the incidence of ergative marking on the agent of speaking. In the case of 'inner speech' this hypothesis is supported by the patterns of subject case-marking found with the other instances of it. In the 1774-line transcript we have found a total of eight instances of inner speech which are framed by verbs with an explicit NP subject. The ergative case marker is used on only one of them ${ }^{16}-$ in contrast to the overall rate of ca. $62 \%$ ergative marking for the subjects of clauses which frame locutions. I turn now to some other kinds of intermediate cases.

The following example comes from a discussion in the dispute concerning the paternity of the speaker's recently born baby girl:

\footnotetext{
${ }^{15}$ Within its discourse context as shown in the transcript (Merlan and Rumsey, 1986:177), it is clear that this is an instance of indirect discourse, i.e., that the subject of pubuda is different from that of the following framing verb construction nyik pilyini. But a sentence of the same form could also have a direct discourse reading 'You may think [with respect to yourself] "I'll go" '.

${ }^{16}$ This occurs in line 1176, where the ergative-marked subject is eni-n, 'you(PL)-ERG'. The other instances, with non-ergative subjects, occur in lines 296, 1131, 1137, 1176.
} 
(64)
na ya aunsiyl nyi-ki-r-iyli
de aunsiyl mel abolayl mi-ri-bul
I here many say/speak-PPR-1SG-Def day many like girl bear-RP-2DU
I say a lot of times, after many days [of copulating] we produced the girl.

The nyikir in (64) exemplifies what Austin (1962) would have called a 'performative' use of nyi- 'say/speak', where the speaker frames what he is saying in the here and now with a verb which refers explicitly to the very speech act in which he is saying it. ${ }^{17}$ When occurring as the subject in such a performative context, the pronoun $n a$ seldom takes the ergative case. This can be related to the fact that in these contexts there is a minimal degree of individuation between the framed utterance and the one which frames it: both belong to the same actual moment of speaking, by the same speaker.

Other examples of performative uses of nyi- which show the same pattern as above are (65) and (66), both of which are common expressions in Ku Waru, but neither of which happens to occur in the textual sample used here. As can be seen, in both expressions the subject pronoun occurs without the ergative case marker. I have never heard the ergative marker used with it in either expression.

$$
\begin{aligned}
& \text { na } m o l \text { nyi-ki-r } \\
& \text { I no say/speak-PPR-1SG } \\
& \text { I say no. } \\
& \text { na age anumuyl nyi-ki-r } \\
& \text { I thank.you very.big say/speak-PPR-1SG } \\
& \text { I (say) thank you very much. }
\end{aligned}
$$

In by far the majority of instances of performative uses of nyikir there is no explicit subject pronoun. ${ }^{18}$ Within a textual sample of 3594 lines (including both the 1744-line transcript in Merlan and Rumsey, 1986, used elsewhere in this article, and the 1850-line transcript in Merlan and Rumsey, 1991:245-321) I found only six instances of clauses that include them. The ergative marker occurred with a subject pronoun in only one of the those six ${ }^{19}$ in contrast to the overall rate of $62 \%$ for speaker NPs of framed locutions. The sample size is too small for this difference to be statistically significant by itself, but taken in combination with commonplace examples such as (65) and (66) it does provide prima facie evidence for a lower transitivity status for clauses which frame performative utterances than for those which frame other locutions.

Another class of framings for which ergative subject-marking seems to be less frequent are ones in which the framed material is indirect discourse, i.e., reported speech in which the indexical categories of person, tense, spatial deixis, etc. are shifted so as to ground them in the speech situation of the 'reporting' event rather than the 'reported' one. The use of indirect discourse is rare in Ku Waru but it does occur. An example may be found in (62), where the presumed 'inner speech' of the addressee is framed from the speaker's point of view, i.e., with a first person subject. Other examples are (67) and (68).

$$
\begin{aligned}
& \text { ab-ayl nunu-nga rong-te mol nyi-ki-m-ayl } \\
& \text { woman-DEF she.herself-GEN fault-IDF no say/speak-PPR-3SG-DEF } \\
& \text { The woman says it was not her own fault. }
\end{aligned}
$$

\footnotetext{
${ }^{17}$ One referee has questioned whether this could be the case in view of the fact that the verb of saying in this example is in what Merlan and I call the present progressive tense/aspect. In that respect the label we have chosen for this category is perhaps misleading, since there is no contrasting non-durative category of present tense within Ku Waru, and hence no formal distinction associated with the distinction between performative and non-performative utterances of the kind that Austin noticed when he pointed out that "I am pronouncing you man and wife" is not a well-formed performative utterance in English. (For details concerning Ku Waru tense/aspect categories, see Merlan and Rumsey, 1991:326-329.)

${ }^{18}$ This is true of Ku Waru clauses in general, as noted above. But it is true in an even higher proportion of clauses with first person singular subjects, and among those, in what is probably an even higher proportion of the ones functioning as performatives.

${ }^{19}$ For the exceptional case where the ergative marker is used in such a context see line 122 of the transcript in Merlan and Rumsey (1986). For the other more usual instances where it is not, see lines 1438, 1571 and 699 of that transcript (699 being the sentence shown in 42) above, and Merlan and Rumsey (1991:259, line 353). Note that in the latter example na nyibu nyikir translates literally as 'I am saying "I will say", , and that the interlinear free translation given for line 1438 in Merlan and Rumsey (1986) does not take account of the words na nyikir 'I say' at the end of that line.
} 
ya torukang nu-nga nyi-ki-n kera laime nyi-ki-n

here father-in-law you-GEN say/speak-PPR-2SG bird cassowary say/speak-PPR-2SG

kung nyi-ki-n

[1408]

pig say/speak-PPR-2SG

[The defendant's] father-in-law, yours, you say, the cassowary, you say, the pigs [are yours], you say.

The corresponding direct discourse version of (67) would have had nanu 'I myself' in place of nunu-nga 'she herself', and (68) would have had na-nga 'my' in place of nu-nga. In the 1744-line transcript in Merlan and Rumsey (1986), we found only nine examples of such indirect discourse. Only four of the nine had explicit NP subjects within the clause. Only one of those was ergative-marked. Again, this is a considerably lower proportion than the observed rate of $62 \%$ for locution-framing clauses overall. While the sample size is too small for this finding by itself to be statistically significant, it is consistent with the hypothesis that clauses which frame indirect discourse are lower in transitivity than those which frame direct, and that this can be related to the fact that the indexical grounding of indirect discourse is shifted into the 'reporting' speech situation, giving it a lower degree of individuation as distinct speech event.

Finally, there is a use of nyi-in which it frames an accompanying locution not only with respect to the utterance in which it occurs, but in terms of some more encompassing range of contexts, which include the immediate one, but are not limited to it. An example is (69).

$$
\text { maku-na nyi-ki-mil na kor nyi-lyo }
$$

mark-LOC say/speak-PPR-2/3PL I always say-HAB:1SG

I've always said that what you say is right on the mark [i.e. true, apposite].

Such 'encompassing' uses of nyi- have something in common with performative ones in that the speaker is framing his utterance in the very act of making it. But unlike in the performative uses, he is here also positing a more-or-less indefinitely extended series of other speech situations in which he has said the same thing. I have found only one other such example in the 1744-line sample. ${ }^{20}$ As in (69), its subject appears without the ergative case marker. It is impossible to say how typical this is on the basis of two examples, but both of them are consistent with the interpretation in terms of object individuation, since the scope of the framing in such instances includes the utterance in which it takes place.

In this section I have discussed four varieties of intermediate framing, for which the framed material is a locution, but one which is less highly individuated than in canonical instances of reported speech such as (53)-(56). The four kinds are: inner speech, performatives, indirect discourse and 'encompassing' framings. For each of the these four varieties, in framing clauses with NP subjects, a lower proportion of them in the sample appear with ergative case than in the overall group of 65 framing clauses which frame a locution. While the sample size for each of the four subtypes is too small to yield a statistically significant result, the picture changes if we consider all four of them together under a single category of framed material with reduced individuation. Combining the instances of all four subtypes in that way yields an aggregate sample of 19 instances. ${ }^{21}$ Of those, the subjects are ergative-marked in three and non-ergative marked in 16. Since the overall rate of ergative marking in clauses that frame locutions is $62.12 \%$, under the null hypothesis that there is no correlation between ergative case marking and fully individuated framed material, in what I am calling the 'reduced individuation' category we would also expect a rate of $62.12 \%$ ergative marking, or 11.8 instances, and $36.92 \%$ or 7.2 instances of non-ergative marking. Applying the chi square test to the difference between those expected rates and the observed ones yields a two-tailed $P$ value of less than .0001 , establishing a high degree of statistical significance for this result (i.e., a probability of under $.01 \%$ of finding the observed rates under the null hypothesis).

\footnotetext{
${ }^{20}$ The other example occurs in line 1571: 'I'm here saying "no" '. In both this example and the one shown in (69) the verbs are in habitual aspect, which is part of what makes the presumption of an extended range of framing contexts explicit. If I am right that these 'encompassing' framings less often have ergative-marked subjects than do others which frame more individuated locutions, then they are a context-specific exception to my finding in section 5 that aspect does not in general correlate closely with subject case-marking in Ku Waru.

${ }^{21}$ As detailed above, eight of these are inner speech, six are performatives, four indirect discourse, and two of the 'encompassing frame' type. There is one instance that belongs to two of the categories: the sentence in (62), which is both indirect discourse and inner speech as noted above. Therefore the total number of instances is one less than the sum in each of the four types.
} 
Before leaving the discussion of reported speech in Ku Waru it is relevant to note that, just as in Bunuba, the association between ergative case marking and the subjects of framing clauses is so well established that an ergativemarked NP alone can serve that function even in the absence of a verb. Examples are:

$$
\begin{aligned}
& \text { ab-ayl-n mol kangabola yi-yl-nga } \\
& \text { woman-DEF-ERG no child man-DEF-GEN } \\
& \text { The woman [says]: "No, the child is the man's". }
\end{aligned}
$$

kang-yi-yl-n kangabola na-nga mol
young man-DEF-ERG child I-GEN no
The young man [says]: "The child is not mine".

$$
\text { pi na-n kalya meri lku pu-mulayl pu-p resis to-mulayl }
$$$$
\text { so I-ERG this there house go-FUT:1PL:DEF go-NF:1 compete do-FUT:1PL:DEF }
$$

So I say we'll go in and debate the matter.

Here it is worth recapitulating what Merlan and I observed apropos such instances in our earlier study (Merlan and Rumsey, 2001:224-225): they appear to be systematically related to the difference between the kind of determination one finds between the verb and its object or complement in reported-speech constructions and in other constructions. For most verbs in most languages, there is a more-or-less limited set of nouns or NP types that the verb can take as its object. But where the object or complement is a locution, there is, in Ku Waru, a total determination in the opposite direction: the choice of verb is limited to only one possible one, nyi- 'say/speak'. This verb, qua lexical root, is therefore entirely redundant in such contexts, and serves only to provide syntagmatic slots for the grammatical affixes marking tense, aspect, person and number of the speaker-subject, etc. It is therefore not surprising that the verb in such contexts is sometimes omitted altogether, and that when it is, the ergative marker on its subject becomes obligatory, marking it categorically as an 'agent-of-speaking' NP, since the verb nyi-is the only one that permits such deletion. In the present context it is interesting to note that: (i) exactly the same sort of deletion occurs in Bunuba as exemplified by (31) and (32); (ii) in Bunuba too there is only one verb that is used to frame reported speech; (iii) in Bunuba too there is a high incidence of ergative marking on subjects of verbs of saying - far higher than for any other formally monovalent verb. Given that the two languages are completely unrelated, and that this same set of lexico-syntactic and pragmatic phenomena must have developed independently in the two different speech communities, the fact that the same combination of them is found in Bunuba provides further evidence for functional interrelatedness among them, along the lines developed in Merlan and Rumsey (Merlan and Rumsey, 2001) as summarized above.

To summarize this section, we can see that in Ku Waru just as in Bunuba the 'say' verb is used with a wide range of expressions which project or point to an utterance, that these vary in the extent to which the framed locution is focused on as a distinct speech event, and that there is a corresponding variation in the transitivity of the framing clause as shown by ergative versus non-ergative case marking on its subject.

\section{Conclusions}

In sections 3 and 5 I have provided broad treatments of the phenomenon of OEM in Bunuba and Ku Waru respectively, and argued for the relevance of NP-object individuation as one of key factors. In sections 4 and 6 I have discussed and exemplified the ways in which reported speech is framed in those two languages, showed that OEM plays a major role, and argued for the relevance there too of a kind of individuation - of the framed material as grounded in a distinct speech event from the one in which it is framed. Some of my findings have been based on clearcut statistical evidence, while for others the evidence is statistically weaker or less readily quantifiable. Since findings of latter sorts will be considered less convincing, here I will distinguish between the two kinds of findings and set them out separately.

On the quantitative side, one of my solidly supported findings is that in Bunuba, by far the most common use of ergative case marking for the subjects of formally monovalent verbs is with the verb MA in clauses where that verb is used to frame reported speech. As discussed in section 4, ergative marking in those clauses is approximately 34 times as common as it is in other clauses with monovalent verbs. Given that ergative marking in all other kinds of clauses with both monovalent and bivalent verbs - always presupposes the presence of an object, usually within the same 
clause, I take this as strong evidence that the material framed by the verb of speaking is being treated like a grammatical object, as in the traditional notion of a 'complement'. Somewhat more speculatively for Bunuba, I take the incidence of ergative versus non-ergative case marking on the subject of those clauses to be related to the degree of individuation of the framed locution, and therefore analogous to the difference in degrees of individuation between the NP objects in sentences like (6) and (7) versus (18)-(21).

In Ku Waru also, one of the most solidly supported findings is that ergative marking often occurs on the subjects of verbs which are used to frame reported speech, and that it occurs far more frequently there than on subjects of other intransitive clauses (although its use in intransitive clauses overall is more frequent in $\mathrm{Ku}$ Waru than in Bunuba). Another solidly supported finding is that in Ku Waru as in Bunuba, ergative marking of a subject NP always presupposes the presence of an object, usually within the same clause, but sometimes established within the previous one. Again, as in Bunuba I take this as strong evidence that the material framed by the verb of speaking is being treated like a grammatical object.

Another finding, which pertains to $\mathrm{Ku}$ Waru transitive clauses in general, is that ergative subject-marking is significantly correlated with two kinds of individuation that can be quantified, namely definite-marking and the occurrence of personal pronouns versus other kinds of NPs in object position. Within the sample of Ku Waru clauses of saying, in those which framed a locution (as opposed to expressions referring to kinds of utterances, or where there was no NP object at all) the subjects were significantly more likely to occur with ergative marking - nearly three times as likely - again providing what I take to be solid evidence that the framed material is being treated like an object. Again, I show the incidence of ergative versus non-ergative case marking on the subject of such clauses to be related to the degree of individuation of the framed locutionary object, as in clauses with NP objects. Analysing four different varieties of framings with reduced individuation, I show that when considered together they are negatively correlated with ergative case marking to a high degree.

The analogous treatment of the two different varieties of individuation in both languages is of interest for theories of transitivity and ergativity (optional and otherwise) in several respects. First, along with other more recent work in this area (e.g., Kemmer, 1993; Næss, 2007) it allows us to extend and refine the Hopper and Thompson (1980) model of transitivity with respect to the notion of object individuation as a relevant component of transitivity. Hopper and Thompson's use of this notion, building upon the work of Timberlake $(1975,1977)$, was an important breakthrough, but its possible application to the analysis of reported speech constructions was not anticipated by them, and was only briefly suggested in Munro (1982:316), which was the first work to apply the Hopper and Thompson framework to constructions of this kind. Following up on Munro's findings, Hopper (1985:73-74, 77) treats reported speech constructions as generally of low transitivity, and those that frame direct discourse as "perhaps" of lower transitivity than those framing indirect (73). While the latter claim is consistent with the limited evidence that Hopper presents in support of it (Hopper, 1985:74), which is drawn entirely from English, the evidence presented here for Bunuba and Ku Waru supports the opposite conclusion, as I have argued above. This may be an area of considerable cross-linguistic variation, just as has been found to be the case regarding the transitivity of reported speech constructions more generally (De Roeck, 1994; Güldemann and von Roncador, 2002). In order to understand why, let us return to the notion of factitive objects that was briefly discussed above.

Hopper (1985) in fact takes that notion as a starting point. Drawing on Lyons (1977:491-494) and Lord (1982), he distinguishes between what he calls 'affected' objects, or 'A-objects', where the referent of the object NP exists independently of the action predicted by the verb and is affected by it, and 'effected objects' or 'E-objects' (Fillmore's factitives), where the referent is brought into existence through that action. In a generalization that has recently been corroborated with more extensive cross-linguistic evidence by Næss (2007), Hopper argues that, other things being equal, clauses with E-objects are universally of lower transitivity than ones with A-objects. Consistent with my opening discussion of reported speech complements as factitive objects, Hopper sees them as E-objects and accounts for their relatively low transitivity on that basis. Taking direct quotations to be of higher 'effectivity' than indirect discourse, he accounts for the presumed lower transitivity of their framing clauses on that basis (Hopper, 1985:74).

The main way in which this paper adds to that discussion is by bringing in evidence regarding Hopper and Thompson's other object property besides affectedness, namely individuation. To the extent that there is crosslinguistic variation and/or intralinguistic instability regarding the transitivity of direct-discourse constructions versus indirect-discourse ones, this may be related to the fact that individuation and affectedness may be in competition with each other. So, for example, direct quotations are of higher 'effectivity' than indirect discourse insofar as the reported locution has purportedly come into existence solely through act of speaking that is predicated by the verb of saying, 
and hence rank lower in terms of 'affectedness', but they generally rank higher in terms of 'individuation' as discussed in this paper. In both Bunuba and Ku Waru, the latter factor seems generally to be a more important component of their transitivity than the former. In other languages, including English, the converse may be true as suggested by Hopper. If so, this may be related to the fact that direct discourse is vastly more frequent in both $\mathrm{Ku}$ Waru and Bunuba than indirect, whereas indirect discourse is quite commonly used in English, and much more fully grammaticalized there than it is in Bunuba or $\mathrm{Ku}$ Waru (along with a range of intermediate varieties of 'semi-indirect' discourse). Accordingly, I suggest as a hypothesis for further investigation, that in languages where there is evidence for differential transitivity of reported speech framings, individuation will figure more centrally as an object property of the framed material in languages where little or no use is made of indirect discourse than in languages where it is common and fully grammaticalized.

That object individuation and affectedness can be competing components of transitivity even in Ku Waru is suggested especially by the uniformly low transitivity of 'performative' framings of reported speech - by default, since they provide a case where the two components are not in competition with each other. That is, such framings always involve both low individuation for the reasons discussed above, and maximal 'effectivity' (which for Hopper, 1985 entails low 'affectedness'), since the speaking of the framed locution itself brings the object of the framing verb into being, whereas in other instances of reported speech it is another predicated act of speaking which does so.

Another way in which the results of this study bear upon the theory of transitivity is in the area what has been called 'grammatical metaphor'. One of the ways in which Hopper and Thompson's initial framework has since been refined is by taking more account of the difference between factors pertaining to the discourse status of a particular referring expression in context, and inherent lexical properties of particular NP types, and the interactive relationship between the two (e.g., Thompson and Hopper, 2001; Næss, 2007). I suggest that new light can be shed on that relationship by focusing on the ways in which features at the lexico-grammatical level and those at the level of the speech situation can align metaphorically. From this point of view it is interesting to find that the discourse grammar of both Bunuba and Ku Waru treats the relative degree of individuation of speech events as analogous to that of the referents of NPs. In other words, the meta-linguistic relationship between one utterance and another (the framing one and the framed one) is treated as analogous to the relationship between 'Agent' and 'Patient' within other kinds of clauses. ${ }^{22}$

Finally, my results confirm and extend Hopper and Thompson's finding that individuation must in at least some contexts be treated not just as a property of the object per se, but of the object in relation to the rest of the construction in which it occurs (cf. Kemmer, 1993; Næss, 2007). So, for example in all the Bunuba and Ku Waru examples considered above, the relevant 'object property' was a matter of the extent to which the reported utterance was being focussed on as distinct from the utterance in which it was being framed. This is analogous, at the meta-linguistic level, to Hopper and Thompson's finding that object individuation for NP objects of the more usual sort (i.e., objects of other verbs besides framing verbs) is a relational property, and at least in part a matter of the degree of distinctness between the referent of the object NP and that of its associated subject NP in a given clause (so that reflexive clauses for example tend to be associated with other low-transitivity features besides reflexivisation).

In short the concept of 'individuation' allows us to build a bridge between our analysis of reported speech constructions and wider issues of transitivity and syntactic case marking. Insofar as OEM figures in the marking of such individuation, as in the languages treated here, it provides a very useful entree into the understanding of those more general issues.

\section{Acknowledgements}

For their helpful comments on and corrections to various drafts of this paper I would like to thank Rachel Hendry, Darja Hoenigman, Nick Evans, Bill McGregor, Francesca Merlan, Lila San Roque, Tasaku Tsunoda, Jean-Christophe Verstraete, and three anonymous referees. For bibliographic assistance, many thanks to Paul Hopper and Sandra Thompson. For funding my research on Bunuba and Ku Waru over the years, I acknowledge the Australian Institute of Aboriginal and Torres Straight Islander Studies, the University of Sydney, Australian National University, the U.S. National Science Foundation and the Australian Research Council.

\footnotetext{
${ }^{22}$ See Silverstein (1981:233-243) for a related argument, based on other kinds of evidence, that the speech event itself, and the participant roles it presupposes, have a prototypical status as a model for the other kinds of events which are predicated within it (cf. Merlan and Rumsey, 2001).
} 


\section{Appendix A. Abbreviations and symbols not included in the Leipzig Glossing Rules}

\begin{tabular}{|c|c|}
\hline CTV & continuative \\
\hline HAB & habitual \\
\hline HRT & hortative \\
\hline IDF & indefinite \\
\hline MA & an atelic monovalent verb root usually glossable as 'say' or 'do' \\
\hline MA2 & telic bivalent verb root \\
\hline NF & non-final verb \\
\hline NSG & non-singular \\
\hline OPT & optative \\
\hline $\operatorname{PPr}$ & present progressive \\
\hline $\mathrm{R}$ & restricted person (extensionally equivalent to first person dual and first person plural exclusive) \\
\hline RA & monovalent verb root, atelic \\
\hline RA2 & bivalent verb root, telic \\
\hline $\mathrm{RP}$ & remote past \\
\hline SUB & subordinate clause \\
\hline $\mathrm{U}$ & unrestricted (extensionally equivalent to first person plural, but refers to at least three individuals) \\
\hline WA & monovalent verb root, telic \\
\hline WU & monovalent verb root, telic \\
\hline WU2 & bivalent verb root, telic \\
\hline YHA & bivalent verb root, telic \\
\hline$<,>$ & acting upon (e.g., $1 \mathrm{sg}>3 \mathrm{sg}$ 'first person singular agent acting upon third person singular subject) \\
\hline- & clearly segmentable morpheme boundary \\
\hline : & morpheme boundary that is not clearly segmentable in surface form \\
\hline ' & boundary between preverb and inflecting root in Bunuba \\
\hline
\end{tabular}

\section{References}

Anderson, N., Wade, M., 1988. Ergativity and control in Folopa. Language and Linguistics in Melanesia 19, 1-16.

Austin, J., 1962. How to do Things with Words. Oxford University Press, Oxford.

Bolkestein, A., 1990. Sentential complements in functional grammar. In: Nuyts, J., Bolkestein, A., Vet, C. (Eds.), Layers and Levels of Representation in Language Theory. Benjamins, Amsterdam, pp. 71-100.

Bolkestein, A., 1992. Limits to layering: locability and other problems. In: Fortescue, M., Harder, P., Kristoffersen, L. (Eds.), Layered Structure and Reference in a Functional Perspective. Benjamins, Amsterdam, pp. 387-408.

Coate, H., 1965. A recent murder trial, Derby (Unpublished typescript of Bunuba text recorded, transcribed and translated by Coate).

Croft, W., 2002. Typology and Universals. Cambridge University Press, Cambridge.

Davidson, D., 1968/1969. On saying 'that'. Synthese 19, 130-146.

Davidson, D., 1984. Inquiries into Truth and Interpretation. Clarendon Press, Oxford, pp. 42-140.

De Roeck, M., 1994. A functional typology of speech reports. In: Engberg-Pedersen, E., Jakobson, L., Rasmussen, S. (Eds.), Function and Expression in Universal Grammar. Mouton, Berlin, pp. 331-351.

Dik, S., 1989. The Theory of Functional Grammar. Part 1: The Structure of the Clause. Foris, Dordrecht.

Dixon, R., 1972. The Dyirbal Language of North Queensland. Cambridge University Press, Cambridge.

Dixon, R., 1994. Ergativity. Cambridge University Press, Cambridge.

Dixon, R., 2002. Australian Languages: Their Nature and Development. Cambridge University Press, Cambridge.

Donohue, C., Donohue, M., 1997. Fore case marking. Language and Linguistics in Melanesia 28, 69-98.

Donohue, M., 2005. Configurationality in the languages of New Guinea. Australian Journal of Linguistics 25, 181-218.

Fillmore, C., 1968. The case for case. In: Bach, E., Harms, R. (Eds.), Universals in Linguistic Theory. Holt, Rinehart and Winston, New York, pp. $1-68$.

Foley, W., 1986. The Papuan Languages of New Guinea. Cambridge University Press, Cambridge.

Foley, W., 2005. Semantic parameters and the unaccusative split in the Austronesian language family. Studies in Language 29, $385-430$.

Givón, T., 1980. The binding hierarchy and typology of complements. Studies in Language 4, 333-377.

Güldemann, T., von Roncador, M. (Eds.), 2002. Reported Discourse: A Meeting Ground for Different Linguistic Domains. Benjamins, Amsterdam. Halliday, M., 1985. An Introduction to Functional Grammar. Arnold, London. 
Haviland, J., 1979. Guugu Yimidhirr. In: Dixon, R., Blake, B. (Eds.), Handbook of Australian Languages. ANU Press, Canberra, pp. $27-180$. Hengeveld, K., 1989. Layers and operators in functional grammar. Journal of Linguistics 25, 125-157.

Hopper, P., 1985. Causes and affects. In: Eilfort, W., Kroeber, P., Petersonet, K. (Eds.), Papers from the Parasession on Causatives and Agentivity. CLS 21, Part 2. Chicago Linguistic Circle, Chicago, pp. 67-88.

Hopper, P., Thompson, S., 1980. Transitivity in grammar and discourse. Language 56, 251-299.

Kamerzell, F., Peust, C., 2002. Reported speech in Egyptian: forms, types and history. In: Güldemann, T., von Roncador, M. (Eds.), pp. $289-322$. Kemmer, S., 1993. The Middle Voice. Benjamins, Amsterdam.

Kimberley Language Resource Centre, 1998. Thangani Bunuba: Bunuba Stories. KLRC, Halls Creek.

Longacre, R., 1985. Sentences as combinations of clauses. In: Shopen, T. (Ed.), Language Typology and Syntactic Description. Cambridge University Press, Cambridge, pp. 235-286.

Lord, C., 1982. The development of object markers in serial verb languages. In: Hopper, P., Thompson, S. (Eds.), Studies in Transitivity. Academic Press, New York, pp. 277-300.

Lyons, J., 1977. Semantics, vol. 2. Cambridge University Press, Cambridge.

McGregor, W., 1990. Functional Grammar of Gooniyandi. Benjamins, Amsterdam.

McGregor, W., 1992. The semantics of ergative marking in Gooniyandi. Linguistics 30, 275-318.

McGregor, W., 1994. The grammar of reported speech and thought in Gooniyandi. Australian Journal of Linguistics 14, 63-92.

McGregor, W., 1997. Semiotic Grammar. Clarendon Press, Oxford.

McGregor, W., 1998. "Optional” ergative marking in Gooniyandi revisited: implications to the theory of marking. Leuvense Bijdragen 87, 491-534.

McGregor, W., 2002. Verb Classification in Australian Languages. Mouton, Berlin.

McGregor, W., 2006. Focal and optional ergative marking in Warrwa. Lingua 116, 393-423.

Merlan, F., Rumsey, A., 1986. A marriage dispute in the Nebilyer Valley. Papers in New Guinea Linguistics 25, 69-180.

Merlan, F., Rumsey, A., 1991. Ku Waru: Language and Segmentary Politics in the Western Nebilyer Valley, Papua New Guinea. Cambridge University Press, Cambridge.

Merlan, F., Rumsey, A., 2001. Aspects of clause structure and reported speech in Ku Waru. In: Pawley, A., Ross, M., Tryon, D. (Eds.), The Boy from Bundaberg: Studies in New Guinea Area Linguistics in Honour of Tom Dutton. Pacific Linguistics, Canberra, pp. $215-231$.

Mithun, M., 1991. Active/agentive case marking and its motivations. Language 67, 510-546.

Munro, P., 1982. On the transitivity of 'say' verbs. In: Hopper, P., Thompson, S. (Eds.), Studies in Transitivity. Academic Press, New York, pp. 301-318.

Næss, A., 2007. Prototypical Transitivity. Benjamins, Amsterdam.

Noonan, M., 1985. Complementation. In: Shopen, T. (Ed.), Language Typology and Syntactic Description. Cambridge University Press, Cambridge, pp. $42-100$.

Partee, B., 1973. The syntax and semantics of quotation. In: Anderson, S., Kiparsky, P. (Eds.), A Festschrift for Morris Halle. Holt, Rinehart and Winston, New York, pp. 410-418.

Potts, D., James, D., 1988. Split ergativity in Siane: a study in markedness. Languages and Linguistics in Melanesia 18, 71-108.

Ransom, E., 1986. Complementation: Its Meanings and Forms. Benjamins, Amsterdam.

Reesink, G., 1993. "Inner Speech" in Papuan languages. Language and Linguistics in Melanesia 24, 217-225.

Rosenbaum, P., 1967. The Grammar of English Complement Constructions. MIT Press, Cambridge, Mass.

Rosier, L., 1999. Le Discourse Rapporté: Histoire, Théorie, Pratiques. Duculot, Paris.

Rumsey, A., 1982. An Intra-Sentence Grammar of Ungarinjin, North-Western Australia. Pacific Linguistics, Canberra.

Rumsey, A., 1990. Wording, meaning, and linguistic ideology. American Anthropologist 92, 346-361.

Rumsey, A., 1994. On the transitivity of 'say' constructions in Bunuba. Australian Journal of Linguistics 14, 137-153.

Rumsey, A., 2000. Bunuba. In: Dixon, R., Blake, B. (Eds.), Handbook of Australian Languages, vol. 5. Oxford University Press, Oxford, pp. 34-153.

San Roque, L., 2008. An introduction to Duna grammar. PhD Dissertation, Australian National University.

Silverstein, M., 1981. Case marking and the nature of language. Australian Journal of Linguistics 1, 227-244.

Silverstein, M., 2003. Indexical order and the dialectics of sociolinguistic life. Language and Communication 23, 193-229.

Steever, S., 2002. Direct and indirect discourse in Tamil. In: Güldemann, T., von Roncador, M. (Eds.), 2002, pp. 91-108.

Stockwell, R., 1977. Foundations of Syntactic Theory. Prentice Hall, Englewood Hills, New Jersey.

Thompson, S., Hopper, P., 2001. Transitivity, clause structure, and argument structure: evidence from conversation. In: Bybee, J., Hopper, P. (Eds.), Frequency and the Emergence of Linguistic Structure. Benjamins, Amsterdam, pp. 27-60.

Timberlake, A., 1975. Hierarchies in the genitive of negation. Slavic and East European Journal 19, 123-138.

Timberlake, A., 1977. Reanalysis and actualization in syntactic change. In: Li, C. (Ed.), Mechanisms of Syntactic Change. University of Texas Press, Austin, pp. 141-177.

Tsunoda, T., 1981. Split case-marking patterns in verb types and tense/aspect/mood. Linguistics 19, 389-438.

Tsunoda, T., 1985. Remarks on transitivity. Journal of Linguistics 21, 385-406.

Vázquez Rozas, V., 1999. Biactant Spanish clauses: syntactic markedness and semantic prototype. In: de Stadler, L., Eyrich, C. (Eds.), Issues in Cognitive Linguistics. Mouton, Berlin, pp. 491-503.

Voloshinov, V., 1973 [1927]. Marxism and the Philosophy of Language. Seminar Press, New York.

Wirrunmarra, B., Marr, J., Oscar, B., 1990. Bunuba Stories. Unpublished booklet prepared by Alan Rumsey (Copies available on request from Alan Rumsey). 